\title{
Treatment of non-ideality in the SPACCIM multiphase model - Part 1: Model development
}

\author{
A. J. Rusumdar ${ }^{1, a}$, R. Wolke ${ }^{1}$, A. Tilgner ${ }^{1}$, and H. Herrmann ${ }^{1}$ \\ ${ }^{1}$ Leibniz Institute for Tropospheric Research (TROPOS), Leipzig, Germany \\ ${ }^{a}$ now at: Institute for Micro Process Engineering, Karlsruhe Institute of Technology, Karlsruhe, Germany \\ Correspondence to: R. Wolke (wolke@tropos.de)
}

Received: 26 March 2015 - Published in Geosci. Model Dev. Discuss.: 1 June 2015

Revised: 15 October 2015 - Accepted: 11 December 2015 - Published: 25 January 2016

\begin{abstract}
Ambient tropospheric deliquesced particles generally comprise a complex mixture of electrolytes, organic compounds, and water. Dynamic modeling of physical and chemical processes in this complex matrix is challenging. Thus, up-to-date multiphase chemistry models generally do not consider non-ideal solution effects. Therefore, the present study was aimed at presenting further development of the SPACCIM (Spectral Aerosol Cloud Chemistry Interaction Model) through treatment of solution non-ideality, which has not been considered before. The present paper firstly describes the model developments including (i) the implementation of solution non-ideality in aqueous-phase reaction kinetics in the SPACCIM framework, (ii) the advancements in the coupling scheme of microphysics and multiphase chemistry and (iii) the required adjustments of the numerical schemes, especially in the sparse linear solver and the calculation of the Jacobian. Secondly, results of sensitivity investigations are outlined, aiming at the evaluation of different activity coefficient modules and the examination of the contributions of different intermolecular forces to the overall activity coefficients. Finally, first results obtained with the new model framework are presented.

The SPACCIM parcel model was developed and, so far, applied for the description of aerosol-cloud interactions. To advance SPACCIM also for modeling physical and chemical processes in deliquesced particles, the solution non-ideality has to be taken into account by utilizing activities in reaction terms instead of aqueous concentrations. The main goal of the extended approach was to provide appropriate activity coefficients for solved species. Therefore, an activity coefficient module was incorporated into the kinetic model framework of SPACCIM. Based on an intercompar-
\end{abstract}

ison of different activity coefficient models and the comparison with experimental data, the AIOMFAC approach was implemented and extended by additional interaction parameters from the literature for mixed organic-inorganic systems. Moreover, the performance and the capability of the applied activity coefficient module were evaluated by means of water activity measurements, literature data and results of other activity coefficient models. Comprehensive comparison studies showed that the SpactMod (SPACCIM activity coefficient module) is valuable for predicting the thermodynamic behavior of complex mixtures of multicomponent atmospheric aerosol particles. First simulations with a detailed chemical mechanism have demonstrated the applicability of SPACCIM-SpactMod. The simulations indicate that the treatment of solution non-ideality might be needed for modeling multiphase chemistry processes in deliquesced particles. The modeled activity coefficients imply that chemical reaction fluxes of chemical processes in deliquesced particles can be both decreased and increased depending on the particular species involved in the reactions. For key ions, activity coefficients on the order of $0.1-0.8$ and a strong dependency on the charge state as well as the RH conditions are modeled, implying a lowered chemical processing of ions in concentrated solutions. In contrast, modeled activity coefficients of organic compounds are in some cases larger than 1 under deliquesced particle conditions and suggest the possibility of an increased chemical processing of organic compounds. Moreover, the model runs have shown noticeable differences in the $\mathrm{pH}$ values calculated with and without consideration of solution non-ideality. On average, the predicted $\mathrm{pH}$ values of the simulations considering solution non-ideality are -0.27 and $-0.44 \mathrm{pH}$ units lower under 90 and $70 \% \mathrm{RH}$ con- 
ditions, respectively. More comprehensive results of detailed SPACCIM-SpactMod studies on the multiphase processing in organic-inorganic mixtures of deliquesced particles are described in a companion paper.

\section{Introduction}

The troposphere is a complex multiphase and multicomponent environment with simultaneous occurrence of heterogeneous chemical transformations, which potentially can alter the composition of tropospheric aerosols (Ravishankara, 1997). In order to access the impact of physico-chemical and dynamical processes associated with aerosol particles, a variety of multiphase chemistry mechanisms have been developed and coupled with atmospheric models (Binkowski and Roselle, 2003; Fast et al., 2006; Seinfeld and Pandis, 2006). During the last decade, some progress was made in evaluating the role of chemical aqueous-phase processes in deliquesced particles and cloud droplets (see, e.g., Hallquist et al., 2009; Tilgner and Herrmann, 2010; Ervens et al., 2011; Tilgner et al., 2013; Guo et al., 2014). Beside the multiphase chemistry developments and findings, the inclusion of reliable thermodynamic modules in multiphase models is required in order to adequately calculate the particle deliquescence, associated water content, chemical reactions and phase transfer processes in multicomponent aerosols at given conditions. Furthermore, these modules are in demand to compute the reactive mass transfer driving forces for dynamic gas-particle partitioning of various semi-volatile species considering complex chemical transformations in aqueous phase.

The calculation of gas to particle partitioning of water, semi-volatile inorganic and organic compounds requires the corresponding vapor pressures, which depend on the saturation vapor pressures of pure compounds and the activity coefficients in the liquid mixture. The Köhler theory (Köhler, 1936) gives a relation between the equilibrium saturation ratio $S_{\mathrm{W}}$ of water vapor above an aqueous solution droplet and the droplet equilibrium size:

$S_{\mathrm{w}}=\frac{p_{\mathrm{w}}}{p_{\mathrm{w}}^{\mathrm{o}}}=\frac{\mathrm{RH}}{100}=a_{\mathrm{w}} \exp \left(\frac{2 v_{\mathrm{w}} \sigma_{\mathrm{w}, \mathrm{s}}}{R T r_{\mathrm{drop}}}\right)$,

where $p_{\mathrm{w}}$ is the equilibrium partial pressure of water over the solution droplet, $p_{\mathrm{w}}^{\mathrm{o}}$ is the equilibrium water vapor pressure over a flat surface of pure water, RH (-) is the ambient relative humidity; $\sigma_{\mathrm{w}, \mathrm{s}}\left(\mathrm{N} \mathrm{m}^{-1}\right)$ is the droplet solution surface tension; $R\left(\mathrm{~J} \mathrm{~mol}^{-1} \mathrm{~K}^{-1}\right)$ is the universal gas constant; $T(\mathrm{~K})$ is the temperature; $r_{\text {drop }}(\mathrm{m})$ is mean wet radius of droplet; and $v_{\mathrm{w}}\left(\mathrm{m}^{3} \mathrm{~mol}^{-1}\right)$ is the partial molar volume of water. The water activity $a_{\mathrm{W}}$ is given as the product of the mole fraction of water $x_{\mathrm{w}}$ in a solution and the molality-based water activity coefficient $\gamma_{\mathrm{w}}$, which accounts for the effects of all intermolecular interactions that take place in the solution. Activity coefficients give an indication of the degree of ther- modynamic non-ideality. Such non-ideal conditions can be expected in deliquesced particles, where, e.g., ionic strengths of about 1-45 $\mathrm{mol} \mathrm{L}^{-1}$ (Herrmann, 2003; Herrmann et al., 2015) are present. In a highly concentrated solution, ions and non-water molecules are more close to each other; therefore they influence each other through electrostatic forces or other physical interactions. These intermolecular forces modify the affinity of a substance to transfer from one phase into another phase or to enter into a chemical reaction. Hence a recent review by Herrmann et al. (2015) suggested that for modeling of multiphase chemical processes in a concentrated solution, it is reasonable to consider the non-ideal behavior instead of assuming ideal solutions. Thus, activities have to be used instead of concentrations and the appropriate calculation methods have to be employed in multiphase chemistry models. Consequently, a range of sensitivity studies with models accounting for composition-dependent processes need to be carried out to clarify the role of the non-ideal behavior, e.g., for the tropospheric multiphase chemistry in deliquesced particles and, overall, its inclusion or neglect in aerosol chemistry models.

In order to simulate gas/particle mass transfer in aerosol models, three main approaches (i.e., equilibrium, kinetic (or dynamic), and hybrid) have been used in the literature (Zhang et al., 2004). The equilibrium approach assumes equilibrium between multiple aerosol phases and the ambient gas concentrations reach equilibrium concentrations at the particle surface instantaneously. The kinetic approach does not rely on the instantaneous equilibrium assumption. In this approach, the gas/particle mass transfer due to the difference between the ambient gas concentration and equilibrium gas concentration is explicitly simulated for each particle class. Usually, hybrid models employ the kinetic approach for coarse particles and the equilibrium approach for fine particles. Thus, an aerosol thermodynamic model is an essential part of all three gas/particle mass transfer approaches.

Considerable effort has been devoted to develop a number of thermodynamic models with reliable accuracy and efficiency to simulate aerosol thermodynamic equilibrium. These models treat particle compositions of varying levels of complexity, often associated by the numerical technique chosen and the activity coefficient model applied. They can be divided into two types, i.e., equation-based approach and Gibbs free energy minimization approach. In the equationbased approach (e.g., ISORROPIA II, Fountoukis and Nenes, 2007; Nenes et al., 1998; EQSAM3, Metzger and Lelieveld, 2007; Metzger et al., 2006; EQUISOLV II, Jacobson, 1997; Jacobson et al., 1996; MARS-A, Binkowski and Roselle, 2003; Saxena et al., 1986; MESA, Zaveri et al., 2005b), a set of reactions is assumed to occur in the atmospheric chemical system (including both gas phase and aerosol phase). The equilibrium state is predicted through the solution of the nonlinear equations system. In the Gibbs free energy minimization approach (e.g., AIM, Clegg et al., 1998b, a; GFEMIN, Ansari and Pandis, 1999a; ADDEM, Topping et al., 2005a, 
b; UHAERO, Amundson et al., 2006, 2007), the equilibrium state of the aerosol system is predicted through the solution of minimization of the Gibbs free energy of the system. Some of the thermodynamic models mentioned above have been compared and evaluated in several studies (Ansari and Pandis, 1999b; Zhang et al., 2000; Yu et al., 2005; Metzger et al., 2006). The equilibrium approach assumes that particles are in thermodynamic equilibrium with the corresponding gas phase; i.e., the mass transfer between the phases is instantaneous. However, this assumption must not necessarily be valid for every compound and condition, for example in the case of coarse particles (e.g., Wexler and Seinfeld, 1990). Therefore, the mass transfer has to be described dynamically by using kinetic or hybrid approaches (e.g., MADM by Pilinis et al., 2000). Such aerosol modules, which treat dynamically gas-particle partitioning of inorganic and organic gases coupled to thermodynamics modules, are developed for more general use in 3-D models (e.g., MOSAIC by Zaveri et al., 2008, MADRID by Zhang et al., 2004) or for detailed process descriptions in the laboratory (e.g., ADCHAM by Roldin et al., 2014).

As mentioned above, determining appropriate activity coefficients is required in the thermodynamic models. This was achieved by using both mixing rules and potentially more accurate techniques for calculating the activity coefficients. Attempts at realistic estimation of activity coefficients can be traced back to extensive literature for inorganic electrolyte solutions (e.g., Prausnitz et al., 1986; Pitzer, 1991; Clegg et al., 1998b, a; Nenes et al., 1998; Metzger et al., 2002; Topping et al., 2005a; Zaveri et al., 2005a; Fountoukis and Nenes, 2007). While the interactions between inorganic compounds are relatively well known, interactions between organic components as well as organic-electrolyte mixtures comprised in complex multiphase systems have remained elusive for some time, due to the large number of organic species with highly variable properties available in the gas phase and in ambient particles. Starting with the more conceptual paper of Clegg et al. (2001), several approaches for the treatment of organic-inorganic mixtures in ambient particles were developed and incorporated into thermodynamic models (e.g., Ming and Russell, 2002; Topping et al., 2005b; Erdakos et al., 2006; Metzger et al., 2006; Clegg et al., 2008; Zaveri et al., 2008; Zuend et al., 2008, 2011; Ganbavale et al., 2015). Raatikainen and Laaksonen (2005) have compared different activity coefficient models, and four models were extended by fitting new parameters for aqueous organic-electrolyte solutions. Most of these revised activity coefficient models are based on an extension of the UNIFAC concept. Erdakos et al. (2006) further developed these extended UNIFAC models. Zuend et al. (2008) fitted the interaction parameters for the organic compounds (alcohols and polyols) and inorganic ions. AIOMFAC is based on the LIFAC group-contribution model (Yan et al., 1999) and yet is modified in many respects to better represent relevant species, reference states, and the relative humidity range of the atmosphere. Recently, Zuend et al. (2011), Mohs and Gmehling (2013) and Ganbavale et al. (2015) proposed revised and extended parameterizations for mixtures containing various organic functional groups, water and inorganic ions.

Complex multiphase chemistry models dealing with deliquesced particles usually do neglect or roughly estimate the effect of solution non-ideality on the chemical processing (see, e.g., Tilgner and Herrmann, 2010; Bräuer et al., 2013; Mao et al., 2013; Tilgner et al., 2013; Guo et al., 2014). However, model studies (e.g., Bräuer et al., 2013; Tilgner et al., 2013) implied that deliquesced particles might be a potentially important medium for multiphase chemistry. Thus, the present study was aimed at the implementation of solution non-ideality in aqueous-phase reaction kinetics in the Spectral Aerosol Cloud Chemistry Interaction Model (SPACCIM, Wolke et al., 2005). Accordingly, an activity module has to be implemented in SPACCIM to provide appropriate activity coefficients for dissolved species. The SPACCIM parcel model was originally developed for the dynamical description of chemical and microphysical cloud processes. SPACCIM was successfully applied in several process studies using the CAPRAM complex multiphase mechanism (Herrmann et al., 2005; Tilgner and Herrmann, 2010; Bräuer et al., 2013; Tilgner et al., 2013).

In this paper, we present an extended model approach for the kinetic description of phase transfer and complex multiphase chemistry considering the non-ideality of solutions by means of activity coefficient models. This paper is split into four sections. In Sect. 2, we described the implementation of solution non-ideality in SPACCIM. In subsequent subsections, the coupling between microphysics and multiphase chemistry models as well as the necessary adjustments of numerical schemes is discussed. In Sect. 2.3, the activity coefficient module is introduced that is specifically designed to treat multicomponent mixed organic-inorganic aerosol particles. Section 3 presents an evaluation of the currently implemented activity coefficient module in SPACCIM. In order to validate the model performance and the capability, the model results were compared with available measurements and other activity coefficient models such as mod. LIFAC (Kiepe et al., 2006), E-AIM (Clegg et al., 1998b, a), and AIOMFAC (Zuend et al., 2008). Furthermore, Sect. 3 presents sensitivity studies on the importance of the different interactions and first model results obtained with the new model framework.

\section{Methodology and model development}

\subsection{Multiphase model SPACCIM (original code)}

In this section, a brief summary is provided for the methods used in SPACCIM original code and the current limitations are outlined. The air parcel model SPACCIM was 
developed for the description of simultaneously occurring chemical and physical processes in cloud droplets and deliquesced particles. Thus, SPACCIM combines a complex multiphase chemistry model with a detailed cloud microphysics for a size-resolved particle/droplet spectrum in a box model framework (Wolke et al., 2005). Depending on the used microphysical model, external and internal mixing of aerosol can be taken into account. The activation of droplets is explicitly described. Either the movement of the air parcel can follow a predefined trajectory (e.g., simulated by a 3-D atmospheric model) or the vertical velocity is calculated based on the parcel updraft compared to prescribed environmental conditions. Entrainment and detrainment processes are considered in a parameterized form. The model allows a detailed description of the processing of gases and particles shortly before cloud formation, during the cloud life time and shortly after cloud evaporation (Sehili et al., 2005). The droplet activation depending on the particle size and composition is explicitly described (see Sehili et al., 2005, and Wolke et al., 2005).

All microphysical parameters needed by the multiphase chemistry are taken over from the microphysical model. For this purpose, a robust and efficient coupling scheme between microphysical and multiphase chemical models is implemented. The coupling scheme is adjusted to the applied time integration method and provides time-interpolated values of the microphysical parameters (temperature, water vapor, liquid water content) and time-averaged mass fluxes between different droplet classes caused by microphysical processes (e.g., by aggregation, break up, condensation). Changes in the chemical aerosol composition by gas scavenging and chemical reactions feed back on the microphysical processes (e.g., water condensation growth rates via changes in the Raoult term). Consequently, related processes such as cocondensation (see Topping et al., 2013, for details) are considered in the model.

The multiphase chemistry is performed for ideal solutions assuming well-mixed droplets. Activity coefficients and the diffusion inside of the droplets are not considered. Dissociations are described dynamically as forward and backward reactions. The applied multiphase chemical mechanism (including phase transfer data and kinetic reaction constants) is provided as an input file. Therefore, a high flexibility concerning changes in the chemical mechanism or the replacement of the entire reaction system is guaranteed. For further details, the reader is referred to the original publication by Wolke et al. (2005). The performance of the model was shown for both simple chemical mechanisms considering inorganic chemistry only and for very complex mechanisms of the CAPRAM family, which contain a detailed description of the inorganic and organic chemistry (Herrmann et al., 2005; Tilgner and Herrmann, 2010; Bräuer et al., 2013; Tilgner et al., 2013).

In the published version of SPACCIM (Wolke et al., 2005), the influence of solution non-ideality on multiphase process- ing was not considered. In fact, the assumption of an ideal solution is not valid, particularly for deliquescent particles, where highly concentrated solutions are typically present. Accordingly, the chemical reaction terms in the aqueousphase chemistry have to be modified by using the activities, and therefore an activity coefficient module has to be added. Furthermore, the feedback approach is enhanced by using the calculated water activity for the Raoult term and by the consideration of surface tension effects. The changes in the model code are given in the following subsection.

\subsection{Further development of SPACCIM}

\subsubsection{Mass balance equations}

For the consideration of solution non-ideality effects in SPACCIM, it is required that rate expressions have to be written in terms of species activities, rather than mole fractions or concentrations. The activity $a_{i}$ of species $i$ can be expressed by $a_{i}=\gamma_{i} \cdot m_{i}=\gamma_{i} \cdot c_{i} / L$, where $\gamma_{i}$ denotes the molalitybased activity coefficient, $m_{i}$ the molality and $c_{i}$ the mass concentration of an aqueous-phase species $i$. The liquid water content $L$ is given as the water mass in the corresponding box volume. In the proposed approach, the non-ideal behavior is taken into account by means of activity coefficients. It should be emphasized that the activity coefficient $\gamma_{i}$ depends usually on the concentrations of all species dissolved in the solution.

In Eqs. (1) and (2), the mass balance equations of the modified version of the SPACCIM extended by the treatment of solution non-ideality are presented. In particular, the aqueous concentrations in the original mass balance equations of the SPACCIM (see Eqs. 1 and 2 in Wolke et al., 2005) are replaced by corresponding activities.

The description of both microphysical and multiphase chemical processes is performed for a size-resolved particle/cloud droplet spectrum, which is subdivided into several classes $k=1, \ldots, M$. In each particle/droplet class, $N_{\mathrm{A}}$ aqueous-phase species are treated, which are not necessarily identical to the number of gas-phase species $N_{\mathrm{G}}$. In the SPACCIM parcel model, the prognostic equations for the mass concentrations of a gas-phase chemical species $c_{i^{*}}^{\mathrm{G}}$ and an aqueous-phase chemical species $c_{i}^{k}$ in the $k$ th class have to take into account the chemical productions and degradations, phase transfers, mass transport between different classes caused by microphysical processes, and en-/de-trainment. These processes can be described by the following mass balance equations: 


\subsubsection{Reaction kinetics}

$$
\begin{aligned}
& \frac{\mathrm{d}\left(c_{i^{*}}^{\mathrm{G}}\right)}{\mathrm{d} t}=\underbrace{R_{i^{*}}^{\mathrm{G}}\left(t, c_{1}^{\mathrm{G}}, \ldots, c_{N_{\mathrm{G}}}^{\mathrm{G}}\right)}_{\begin{array}{c}
\text { gas phase } \\
\text { chemistry }
\end{array}}-\underbrace{\kappa_{i} \sum_{k} L_{k} k_{t}^{k i}\left[c_{i^{*}}^{\mathrm{G}}-\frac{a_{i}^{k}}{H_{i}}\right]}_{\begin{array}{c}
\text { phase } \\
\text { transfer }
\end{array}} \\
& +\underbrace{\mu\left[c_{i^{*}}^{\mathrm{G}}-c^{G_{\mathrm{ent}}}\right]}, \\
& \text { entrainment/ } \\
& \text { outflow } \\
& \begin{aligned}
\frac{\mathrm{d}\left(c_{i}^{k}\right)}{\mathrm{d} t}= & \underbrace{L_{k} R_{i}^{A}\left(t, a_{1}^{k}, \ldots, a_{N_{\mathrm{A}}}^{k}\right)}_{\begin{array}{c}
\text { aqueous phase } \\
\text { chemistry }
\end{array}}+\underbrace{\kappa_{i} L_{k} k_{t}^{k i}\left[c_{i^{*}}^{\mathrm{G}}-\frac{a_{i}^{k}}{H_{i}}\right]}_{\begin{array}{c}
\text { phase } \\
\text { transfer }
\end{array}} \\
+ & \underbrace{F\left(c_{i}^{1}, \ldots, c_{i}^{M}\right)}_{\begin{array}{l}
\text { mass transfer } \\
\text { by microphysics }
\end{array}}+\underbrace{\mu\left[c_{i}^{k}-c_{i}^{k_{\text {ent }}}\right]}_{\begin{array}{l}
\text { entrainment } \\
\text { outflow }
\end{array}},
\end{aligned}
\end{aligned}
$$

with $i^{*}=1, \ldots, N_{\mathrm{G}} ; i=1, \ldots, N_{\mathrm{A}} ; k=1, \ldots, M$.

In the above formulation, $L_{k}$ denotes the liquid water content of the $k$ th droplet class inside the box volume. The values $a_{i}^{k}, k=1, \ldots, M$, represent the activities of species $i$ in the $k$ th liquid water fraction. The vector $c^{\mathrm{G}}$ stands for the concentrations of the gas-phase species and $k_{t}^{k i}$ is the mass transfer coefficient. The chemical reaction terms of the corresponding species are denoted by $R_{i^{*}}^{\mathrm{G}}$ and $R_{i}^{\mathrm{A}}$. The second terms on the right-hand side of the aforementioned equations describe the change in mass concentration of the soluble species due to phase transfer between the gas-phase and particle/cloud droplet classes. Hence, this term will be referred to as the Henry term in the following. The value $H_{i}$ denotes here the dimensionless Henry's law coefficient for species $i$. The prefactor $\kappa_{i}$ of the Henry term is a solubility index and defined to be equal to 1 as well as 0 for soluble and insoluble species, respectively (see Wolke et al., 2005). The term $F\left(c_{i}^{1}, \ldots, c_{i}^{M}\right)$ in Eq. (3) stands for the mass transfer between different droplet classes by microphysical exchange processes (e.g., by aggregation, break up, condensation). The time-dependent natural and anthropogenic emissions as well as dry and wet deposition are parameterized in the last terms of the right-hand sides using a time-dependent entrainment/detrainment rate $\mu$. One should note that the above-mentioned mass balance equations are not only limited to the "non-ideal" approach. Whenever, the activity coefficients are defined as unity then this numerical model formulation will reduce to the original version of SPACCIM.
The first terms $R_{i^{*}}^{\mathrm{G}}$ and $R_{i}^{\mathrm{A}}$ on the right-hand sides of the mass balance Eqs. (2) and (3) comprise the chemical transformations (production and degradation fluxes). However, the reaction term included in Eq. (2) is only a function of concentrations of gas-phase species. Since the gas-phase mixture is assumed to behave as an ideal gas-phase mixture, the nonideality is not considered in this term.

Suppose, for an irreversible reaction $A+B \rightarrow C+D$ in the aqueous phase, the reaction rate $r_{A}$ can be written while considering the solution non-ideality as follows:

$r_{A}=-k_{A} \cdot\left[a_{A}\right] \cdot\left[a_{B}\right]=-k_{A} \cdot \gamma_{A}[A] \cdot \gamma_{B}[B]$.

Here, the activities of $A, B, C$, and $D$ are used instead of the concentrations. The activity of $A$ is proportional to its molar concentration (either molality based or mole fraction based) $[A]$, where the proportional constant is the activity coefficient $\gamma_{A}$ of that particular species. The treatment of solution nonideality was also considered for equilibrium reaction types, which should be explained with the generic example shown as

$v_{C} C+v_{D} D \rightleftharpoons v_{A} A+v_{B} B$.

The relative quantities (i.e., thermodynamic activities) of reactants and products in an equilibrium reaction are determined from the equilibrium relation,

$$
\begin{aligned}
\sum_{i}\left\{a_{i}\right\}^{\lambda_{i} \nu_{i}} & =\frac{\{A\}^{\nu_{A}} \cdot\{B\}^{\nu_{B}}}{\{C\}^{\nu_{C}} \cdot\{D\}^{\nu_{D}}} \\
& =\frac{\left(\gamma_{A}^{\nu_{A}} \cdot[A]^{\nu_{A}}\right) \cdot\left(\gamma_{B}^{\nu_{B}} \cdot[B]^{\nu_{B}}\right)}{\left(\gamma_{C}^{\nu_{C}} \cdot[C]^{\nu_{C}}\right) \cdot\left(\gamma_{D}^{\nu_{D}} \cdot[D]^{\nu_{D}}\right)}=K_{\mathrm{eq}},
\end{aligned}
$$

where $K_{\text {eq }}$ called as equilibrium coefficient, $\left\{a_{i}\right\}$ is the thermodynamic activity of species $i,\{A\}$, etc., are individual thermodynamic activities, $\lambda_{i}=+1$ for products, and $\lambda_{i}=-1$ for reactants. As mentioned earlier, activity of a species $A$ is its molality $m_{A}$ multiplied by its activity coefficient $\gamma_{A}$. A solute activity coefficient represents the deviation from ideal behavior of the solute in solution. Hence, the concentration-dependent activity coefficients are estimated for all soluble species. Note that the activity coefficients for neutral inorganic species (such as $\mathrm{O}_{2(\mathrm{aq})}$ ) are defined as unity. At the same time, the activity coefficients of radicals are also defined as unity, since their reactivity is quite fast and lifetime is rather small. The consideration of activities in the SPACCIM framework for different types of species is summarized in Table 1.

\subsubsection{Phase transfer processes}

The dynamical description of phase transfer processes between the gas and liquid phases in SPACCIM is specified according to the Schwartz approach (Schwartz, 1986). During dissolution, the saturation vapor pressure of gas $A$ can be 
Table 1. Description of activities implemented in SPACCIM.

\begin{tabular}{ll}
\hline Activities & Description \\
\hline Activity of a gas over a particle surface & $\left\{A_{(\mathrm{g})}\right\}=p_{A, s}$ \\
Activity of an un-dissociated compound & $\left\{A_{(\mathrm{aq})}\right\}=m_{A} \gamma_{A}$ \\
Activity of an ion in solution & $\left\{A^{+}\right\}=m_{A^{+}} \gamma_{A^{+}}$ \\
Activity of liquid water in a particle & $\left\{\mathrm{H}_{2} \mathrm{O}_{(\mathrm{aq})}\right\}=a_{\mathrm{w}}$ \\
Activity of a solid & $\left\{A_{(\mathrm{s})}\right\}=m_{S}$, i. e., $\gamma_{S}=1$ \\
\hline
\end{tabular}

determined from the equilibrium relationship $A_{\text {(g) }} \rightleftharpoons A_{(\text {aq) }}$. Thus, in terms of an arbitrary gas $i$, Henry's law is defined as

$p_{i, k}^{\mathrm{s}}=\frac{m_{i}^{k}}{K_{i}^{\mathrm{H}}}$,

where $p_{i, k}^{\mathrm{s}}$ is the saturation vapor pressure (atm) of gas phase species $i$ over a particle in size bin $k, m_{i}^{k}\left(\mathrm{~mol} \mathrm{~kg}^{-1}\right)$ is the molality of dissolved gas-phase species $i$ in particle class $k$, and $K_{i}^{\mathrm{H}}\left(\mathrm{mol} \mathrm{kg}^{-1} \mathrm{~atm}^{-1}\right)$ is the corresponding Henry constant. It has to be noted here that the Henry's law constants of an aqueous solution depend on the composition of the aqueous solution, e.g., on the electrolyte identity of the solution (ionic strength, etc.). Non-ideal electrolyte solutions are able to both suppress the uptake ("salting-out") and enhance the uptake ("salting-in") of soluble gases compared to value for pure water uptake (Herrmann et al., 2015). These salting effects can be quantitatively described by the Setschenow equation (Sander, 2015). However, as reported in the review of Sander (2015), there are unfortunately only limited data available. Therefore, salt effects are only considered in SPACCIM due to the consideration of the activity coefficients in the uptake calculation. The model results should be therefore treated with caution particularly at higher ionic strengths of the solution due to the lower range of functionality of Henry's law coefficients compared to the applicability range of present activity coefficient models.

The above-mentioned saturation vapor pressure is related to the saturation vapor mole concentration $c_{i, k}^{\mathrm{s}}\left(\mathrm{mol} \mathrm{m}^{-3}\right)$ by

$p_{i, k}^{\mathrm{s}}=c_{i, k}^{\mathrm{s}} R T$,

where $R$ denotes the universal gas constant in $\left(\operatorname{atm~m} \mathrm{mol}^{-1} \mathrm{~K}^{-1}\right.$ ) and $T(\mathrm{~K})$ the temperature. Then, Eq. (7) can be expressed in terms of concentrations rather than molalities and partial pressures as

$c_{i, k}^{\mathrm{s}}=\frac{p_{i, k}^{\mathrm{s}}}{R T}=\frac{m_{i}^{k}}{K_{i}^{\mathrm{H}} R T}=\frac{m_{i}^{k}}{H_{i}}$.

Here $H_{i}=K_{i}^{\mathrm{H}} R T$ stands for the dimensionless Henry constant. Considering the solution non-ideality in the aqueous phase, the molalities $m_{i}^{k}$ are replaced by the activities $a_{i}^{k}=\gamma_{i}^{k} m_{i}^{k}$. Considering $M$ classes of particles associated, we state the appropriate expression for gas-phase loss while

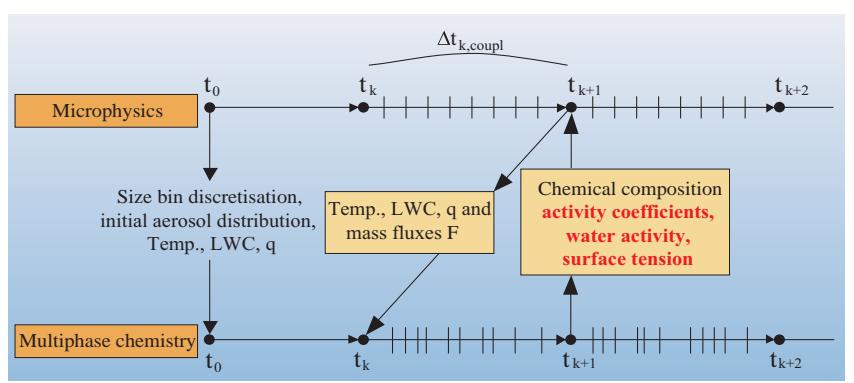

Figure 1. Schematic of the model coupling strategy and its implementation considering the treatment of solution non-ideality and surface tension effects in SPACCIM.

neglecting the Kelvin effect (following Jacobson, 1997):

$\frac{\mathrm{d} c_{i}^{\mathrm{G}}}{\mathrm{d} t}=-\sum_{k} k_{t}^{k i} L_{k}\left(c_{i}^{\mathrm{G}}-\frac{a_{i}^{k}}{H_{i}}\right)$.

Equation (10) pertains to the case of a single gas-phase species equilibrating between the gas and aqueous aerosol phases, with the mass transfer coefficient $k_{t}^{k i}$ defined by

$k_{t}^{k i}=\left(\frac{r_{k}^{2}}{3 D_{i}^{\mathrm{G}}}+\frac{4 r_{k}}{3 v_{i} \alpha_{i}}\right)$,

which depends on the droplet size $r_{k}$, the gas diffusion coefficient $D_{i}^{\mathrm{G}}$, the molecular speed $v_{i}$ and the mass accommodation coefficient $\alpha_{i}$ of the $i$ th species. These quantities play a decisive role in determining the rate of uptake of gaseous species by, and evaporation from aerosol particles, respectively, governing the timescale for a droplet to attain an equilibrium (Schwartz, 1986).

\subsubsection{Coupling scheme}

The coupling between microphysics and multiphase chemistry models in SPACCIM follows the so-called "operator splitting" technique. As described in Sehili et al. (2005), the coupling scheme provides time-interpolated values of the meteorological variables (temperature, water vapor, liquid water content) and generates the time-averaged mass fluxes $F$ over the coupling time interval. The changes in the chemical aerosol composition by gas scavenging and the chemical reactions have a continuous feedback on the microphysical processes (e.g., water condensation growth rates via changes in surface tension and the Raoult term/water activity).

For the "non-ideal" approach in SPACCIM, the coupling scheme is modified, since activity coefficients have to be considered in both models. At the same time, the activity coefficients are repeatedly required to compute the chemical transformations and the phase transfer terms (see Sect. 2.2.2 and 2.2.3). Furthermore, the modified activity coefficients as well as the parameterized surface tension are delivered back to the microphysical model. Figure 1 illustrates this coupling strategy between microphysical and multiphase chemistry model 


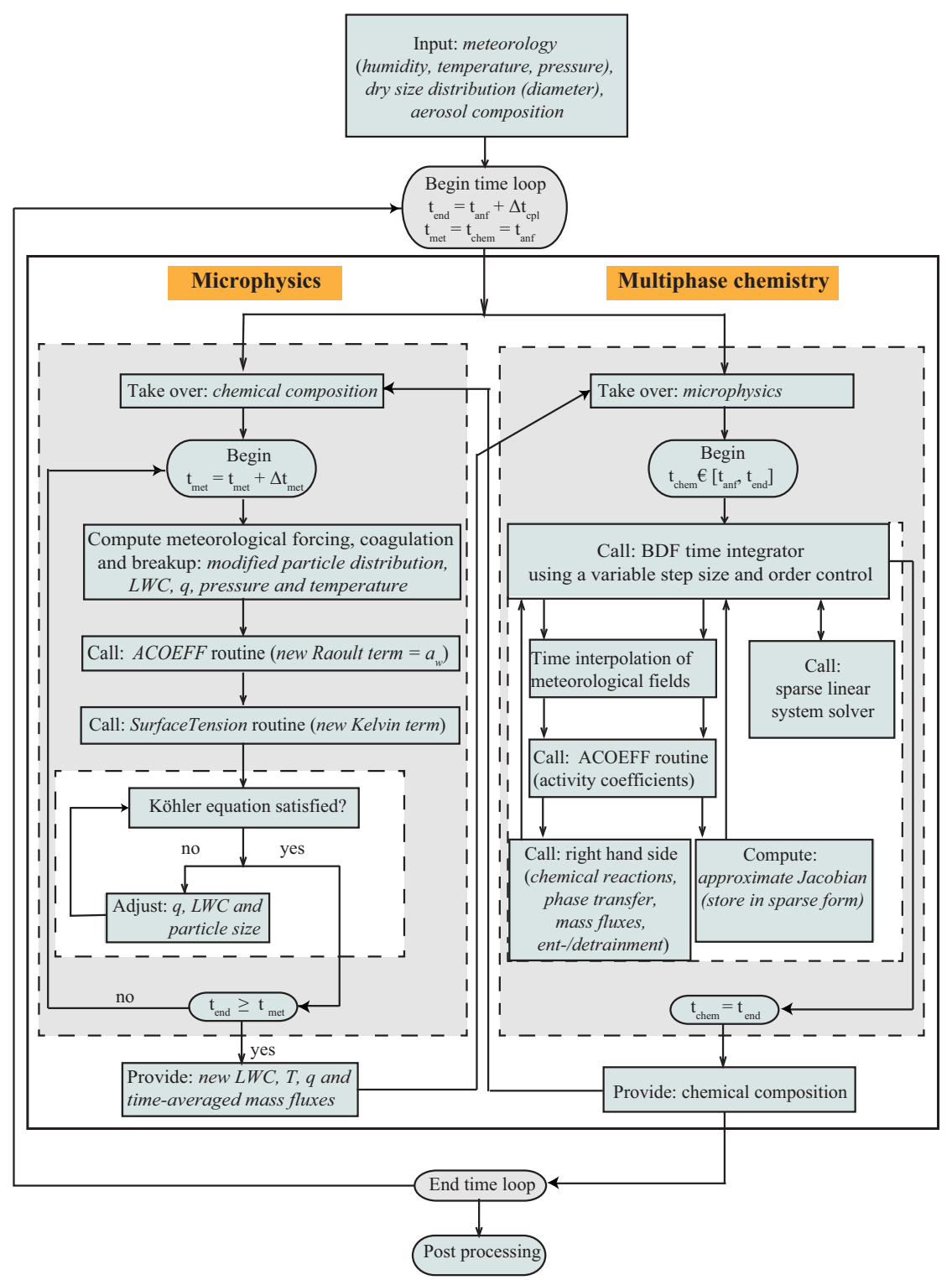

Figure 2. Scheme of activity coefficients and surface tension used in the microphysics and multiphase chemistry models.

as well as their interexchange while considering non-ideal solutions and surface tension effects (see Sect. 2.2.6). The coupling strategy enables a continuous feedback of the multiphase chemistry on the microphysical processes such as water condensational growth. The two models run separately and exchange information at every coupling time step (see Fig. 2). Moreover, both widely separated operating models use its individual time-step control. This is necessary in order to ensure a high flexibility regarding the usage of models with different complexities and numerical efficiency. The coupling between both models and the activity coefficient module utilize well-defined interfaces for the intercommuni- cation of codes while considering the aqueous-phase chemistry in non-ideal solutions. Furthermore, the interpolation and averaging of the required meteorological variables and parameters are arranged and implemented in the same way as described in Wolke et al. (2005).

\subsubsection{Feedback of non-ideal aqueous-phase chemistry on microphysics}

Microphysical processes described in SPACCIM include equilibrium growth of aerosol particles and condensational growth of the droplets (Simmel and Wurzler, 2006). The Köhler equation (see, e.g., Köhler, 1936; Pruppacher and 
Klett, 1997) gives the saturation ratio of water vapor at the particle-air interface, which depends on the chemical composition, the droplet diameter and the surface tension of the particle. In SPACCIM, the non-linear relationship Eq. (1) is used to determine the equilibration of water between the liquid and surrounding vapor phase for non-activated particles. The water saturation pressure in Eq. (1) is affected by the curvature of the particle (also known as Kelvin effect) and the water activity, which is determined by the solutes (Raoult effect). Previously, Wolke et al. (2005) calculated the Raoult term in the condensation rate using osmotic coefficient, according to Pruppacher and Klett (1997). While, the intension was to allow the feedback of chemical particle composition onto microphysics, the Raoult term was replaced by the sum of molar ratios of all soluble species included in the multiphase system:

Raoult $_{\text {chem }}^{k}=\frac{\sum_{i}^{N_{\mathrm{A}}} \mathrm{mol}_{\mathrm{sol}_{i}}^{k}}{\mathrm{~mol}_{\mathrm{w}}^{k}}$.

Here, the quantities $\mathrm{mol}_{\mathrm{sol}_{i}}^{k}$ of soluble material are obtained from the multiphase chemistry. The molar water fraction $\mathrm{mol}_{\mathrm{w}}^{k}$ varies and is taken directly from the microphysics. The Raoult term in Eq. (12) depends on all soluble species. In the non-ideal approach of SPACCIM, the water activity $a_{\mathrm{w}}^{k}$ estimated from the activity coefficient module (see Sect. 2.3) is used directly for the Raoult term in microphysics. On the other hand, the description of change in droplet curvature (Kelvin effect) is treated with surface tension approaches (see Sect. 2.2.6).

Both effects are influenced by the particle composition, which is continuously changed by phase transfer and multiphase processes. However, the mass concentrations of all species are kept fixed for the microphysics over a coupling time step (see Fig. 1). But the molalities and, therefore, the Kelvin and Raoult terms are changed caused by the adjustment of the liquid water content. Equation (1) has to be fulfilled simultaneously for all non-activated particle classes. The droplet activation is described explicitly and takes place for all particles, which grow over the critical radius. The condensation and evaporation of the activated droplet classes are described dynamically. The predicted saturation vapor pressure is used as input into the droplet growth equation. The coupled system for all classes has to be solved simultaneously, whereas the total amount of water (liquid or gaseous) is prescribed. This leads to a nonlinear system, which has to be solved iteratively at each microphysical time step. A more detailed description of the iterative procedure is given in Simmel and Wurzler (2006). A new solution of the system is obtained, and defines the equilibrium saturation ratio and the corresponding particle/droplet diameters. This implies changes in the corresponding liquid water contents and, hence, in the molalities. Consequently, the water activity and the surface tension have to be recalculated at each micro- physical time step. A description of the equilibration algorithm is presented schematically in Fig. 2. Based on this, SPACCIM allows an ongoing feedback of the chemical particle composition onto microphysics. Conversely, the microphysical model provides all microphysical variables for integrating the multiphase chemical system, such as liquid water content, $T$ and the mass fluxes $F$ at the coupling time step (see Fig. 1).

\subsubsection{Surface tension}

Surface-active substances present at the interface and organic compounds dissolved in the solution can significantly influence the surface tension and thus can affect cloud droplet activation and hygroscopic growth (Shulman et al., 1996; Facchini et al., 2000; Tuckermann and Cammenga, 2004; Topping et al., 2007; Prisle et al., 2012). A reduction of surface tension in atmospheric cloud and fog water samples was highlighted in several studies (e.g., Facchini et al., 1999, 2000; Mircea et al., 2002; Nenes et al., 2002). Furthermore, Henning et al. (2005) and Svenningsson et al. (2006) measured a surface tension lowering for organic mixtures in laboratory studies. On the other hand, Sorjamaa et al. (2004) and Sorjamaa and Laaksonen (2006) pointed out that surfaceactive substances can enrich at the particle/droplet surface.

A first specific relationship between water-soluble organic aerosol concentration and surface tension has been derived by fitting the equation of Szyszkowski-Langmuir to Po Valley fog data (Facchini et al., 1999). Model approaches that can estimate the surface tension of inorganic, organic systems and mixed inorganic/organic systems were proposed by Topping et al. (2007). Recently, sophisticated parameterizations were developed for modeling the combined effects of both bulk-surface partitioning and surface tension on cloud droplet activation of organic aerosols (Topping, 2010; Prisle et al., 2011; Raatikainen and Laaksonen, 2011). However, Prisle et al. (2012) suggested neglecting the surfactant effects instead of employing the numerical parameterizations calculating the reduction of surface tension.

Since the present paper is aimed at the treatment of solution non-ideality in a multiphase chemistry model framework, the model development considered the influence of surface tension on droplet activation, as a first step, with more simplified parameterizations of Facchini et al. (1999) and Ervens et al. (2004) only. The implementation of more advanced approaches in SPACCIM will be subject of future development efforts.

In the present work, the following relationship proposed by Facchini et al. (1999) was implemented in the SPACCIM framework:

$\sigma_{\mathrm{w}, \mathrm{s}}^{k}=\sigma_{\mathrm{w}}^{k}-0.01877 \cdot T \cdot \ln \left(1+628.14 \cdot\left[C^{k}\right]\right)$,

where $T$ is the temperature in $\mathrm{K}$ and $\left[C^{k}\right]$ represents the concentration of WSOC (Water Soluble Organic Carbon, 
mol $\mathrm{CL}^{-1}$ ) in particle class $k$. In addition, a combined approach for accounting for a simultaneous change in $\sigma_{\mathrm{w}, \mathrm{s}}^{k}$ and the mean molar mass of solute $M_{\text {sol }}$ derived by Ervens et al. (2004) was also implemented in the present work:

$\sigma_{\mathrm{w}, \mathrm{s}}^{k}=\sigma_{\mathrm{w}}^{k}-0.01877 \cdot T \cdot \ln \left(1+628.14 n_{c} c_{\mathrm{sol}}^{k}\right)$,

where $c_{\text {sol }}^{k}$ is the solute concentration in $\left(\mathrm{mol} \mathrm{L}^{-1}\right)$ and $n_{\mathrm{cb}}$ represents the number of carbon atoms defined by

$n_{\mathrm{cb}}=\frac{M_{\mathrm{sol}}}{2.2 M_{\mathrm{c}}}$,

with $M_{\mathrm{c}}=12 \mathrm{~g} \mathrm{~mol}^{-1}$.

\subsubsection{Adjustment of numerical schemes}

In order to treat aqueous-phase chemistry considering new solution non-ideality effects, the numerical schemes used in Wolke et al. (2005) are required to adjust, mainly, (i) the time integration scheme, (ii) the computation of the Jacobian matrix and (iii) the sparse linear solver. The system of mass balance equations (Eqs. 2 and 3) is integrated in an implicit and coupled manner by higher order backward differential formula (BDF) schemes (e.g., Hairer et al., 1993). In any implicit multistep method, the main computational task is the solution of a non-linear equation of the form:

$\boldsymbol{F}\left(\boldsymbol{c}^{n+1}\right)=\boldsymbol{c}^{n+1}-\boldsymbol{X}^{n}-\beta \Delta t_{n} \boldsymbol{f}\left(t_{n+1}, \boldsymbol{c}^{n+1}\right)=0$,

where $\boldsymbol{f}\left(t_{n+1}, \boldsymbol{c}^{n+1}\right)$ stands for the right-hand side of Eqs. (2) and (3), $\beta>0$ is a parameter of the integration method and $\boldsymbol{X}^{n}$ is a linear combination of previous values. If Eq. (16) is solved by a Newton-like method, the main burden is the approximate solution of linear systems of the form

$$
(\mathbf{I}-\beta \Delta t \mathbf{J}) \Delta \boldsymbol{c}=\boldsymbol{b},
$$

where I denotes the identity matrix and $\Delta t$ represents the time step size. The matrix $\mathbf{J}$ stands for an approximation of the Jacobian $\partial \boldsymbol{f}(t, c) / \partial \boldsymbol{c}$ of the right-hand side of the ordinary differential equation (ODE) system. The vector $\boldsymbol{b}$ is given as

$\boldsymbol{b}=\boldsymbol{c}^{n}-X^{n}-\beta \Delta t_{n} \boldsymbol{f}\left(t_{n}, c^{n}\right)$.

Usually, the dimension of the linear system Eq. (17) is rather high. Large systems can be solved with reasonable effort by iterative or direct sparse solvers, which utilize the special structure of the system (sparsity, block structure, different types of coupling). Such efficient solvers are already developed and applied in the former version of SPACCIM for the "ideal" approach (see Wolke and Knoth, 2002; Wolke et al., 2005 , for further details).

In this case, the Jacobian structure of the right-hand side of the multiphase system (Eqs. 2 and 3) for two droplet classes

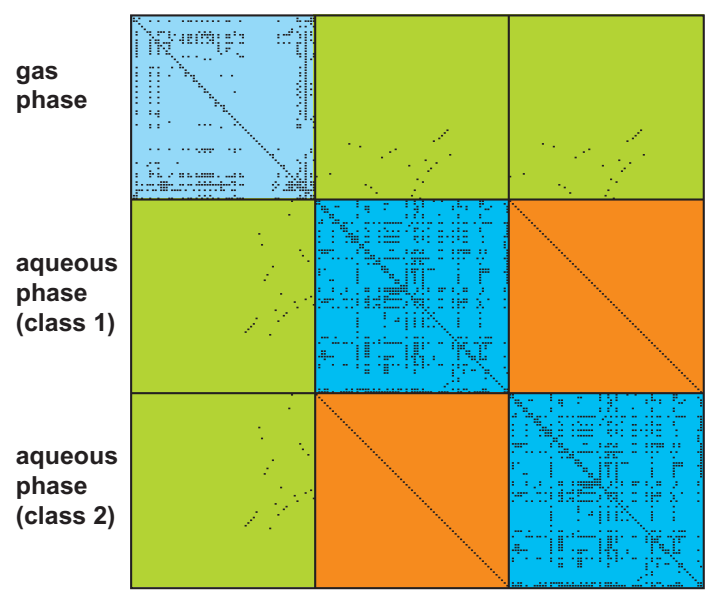

Figure 3. Sparse structure of Jacobian for two droplet classes (adapted from Wolke et al., 2005).

is shown in Fig. 3. As can be seen, the dots are usually nonzero entries means that the species in the row depends on the species in the column. The diagonal elements of the Jacobian describe the dependence from the species itself. These entries can be caused by chemical reactions and phase transfer, but also by the terms from microphysical fluxes and entrainment.

The block structure shown in Fig. 3 can be explained as follows: the blocks in the diagonal correspond to the Jacobian of the gas-phase and aqueous-phase reaction terms, respectively. The upper left block (light blue) represents the gas phase. The other two diagonal blocks (blue) are related to the aqueous-phase chemistry attained to have the same sparse structure. The left and upper boundary blocks (green) represent the phase interchange between gas-phase species and corresponding aqueous-phase species in each class, according to Schwartz (1986). The orange diagonal matrices include the coupling terms resulting from the mass transfer between liquid species and the corresponding species in the other classes. These sparse block matrices are generated explicitly and stored in sparse form. The linear system (see Eq. 18) is solved by a sparse LU decomposition with diagonal pivoting. An optimal order of the pivot elements to avoid fill-in is determined by an adjusted Meis-Markowitz strategy (Wolke and Knoth, 2002). In fact, only an appropriate approximation of the Jacobian is required to ensure the convergence of the Newton-like method for the corrector iteration (Eq. 17). Therefore, the sparse factorization is stored and has to be performed only when the Jacobian $\mathbf{J}$ is recomputed.

The adjusted numerical scheme works robust and very efficient for the "ideal" case. But these effective approaches can only be used in the "non-ideal" case, if the special sparse and block structure can be largely preserved. The calculation of the Jacobian has to be performed by applying the "chain rule" for the aqueous-phase reaction and mass transfer terms in the model equations Eqs. (2) and (3). These terms depend on the activities instead of the molalities in difference to the 
ideal case. While the "outer" derivatives are unchanged, the "inner" derivatives have to be modified. In the case that $c^{k}$ is the vector of all concentrations and $L^{k}$ the liquid water content in the $k$ th droplet class, the gradient with respect to vector $c^{k}$ is denoted as

$\nabla_{c^{k}}=\left(\frac{\partial}{\partial \boldsymbol{c}_{1}^{k}}, \ldots, \frac{\partial}{\partial \boldsymbol{c}_{N_{\mathrm{A}}}^{k}}\right)$.

In the ideal approach, the molalities depend only on the corresponding species itself. Then the gradient of the molalities is given as follows:

$\nabla_{c^{k}} m_{j}^{k}\left(c_{j}^{k}\right)=\frac{1}{L^{k}}(0, \ldots, 0,1,0, \ldots, 0)$.

In the above formulation, the gradient has only one entry in the $j$ th position, which conserves the structure of the "outer" Jacobian. Contrarily, while applying the chain rule, the gradient for non-ideal solutions would be

$$
\begin{aligned}
\nabla_{c^{k}} a_{j}^{k}\left(c^{k}\right) & =\frac{c_{j}^{k}}{L_{k}} \cdot\left(\nabla_{c^{k}} \gamma_{j}^{k}\left(c^{k}\right)\right) \\
& +\frac{1}{L_{k}} \cdot\left(0, \ldots, 0, \gamma_{j}^{k}, 0, \ldots, 0\right),
\end{aligned}
$$

where the gradient $\nabla_{c^{k}}\left(\gamma_{j}^{k}\left(\boldsymbol{c}^{k}\right)\right)$ of activity coefficients depends usually on all concentrations of the vector $\boldsymbol{c}^{k}$ considered in the activity calculations.

The first term in Eq. (21) is a vector with entries in several positions depending on the activity coefficient module. This leads to "fill-in" in the corresponding lines of the Jacobian from aqueous-phase chemistry (blue blocks) and the phase transfer terms (green blocks). Consequently, the efficient direct sparse solvers are used in SPACCIM for the linear system cannot be utilized. However, since only a "good" approximation for the Jacobian is needed, the first term shown in Eq. (21) is omitted assuming that the dependency of the activity coefficients from the concentrations can be neglected over the time step. The second term involves the activity coefficient $\gamma_{j}^{k}$ that yields from the derivative of the activity with respect to molality of that particular species $m_{j}$. Although the derivative of activity coefficients is omitted, the same data structures are obtained as in the ideal case. The second term on the right-hand side of Eq. (21) has the same structure as on the right-hand side of Eq. (20). Only the non-zero entry in the $j$ th position changes from 1 to $\gamma_{j}^{k}$. This leads to modifications of the non-zero entries in the Jacobians of the chemistry (blue blocks) and the phase transfer (green blocks) terms. However, the sparse structure of the systems is conserved effectively.

\subsection{SPACCIM's activity coefficient module}

A main task in the extended approach (Fig. 2) is to provide appropriate activity coefficients for the solved species.
Therefore, several suitable activity models have been tested and compared regarding their suitable applicability in order to achieve the above-mentioned objective (see Sect. 3.1). Overall, AIOMFAC seems to be most qualified for the aimed applications. Therefore, the implementation of the related SpactMod module was performed by using the theoretical framework and the available parameters of Zuend et al. (2008). The AIOMFAC was originally developed for systems composed of organic compounds with $-\mathrm{CH}_{n}(n=0,1$, $2,3)$ and - $\mathrm{OH}$ as functional groups. On the other hand, several authors (e.g., Gilardoni et al., 2009; Liu et al., 2009; Russell et al., 2009; Takahama et al., 2011) reported that other individual organic compounds and compound classes have also a strong impact on multiphase chemical processing on ambient aerosols for instance, aldehydes, ketones, carboxylic acids, and multifunctional organic compounds. Moreover, the aforementioned organic compound classes are almost omnipresent in tropospheric aerosol particles and, therefore, explicitly treated in complex multiphase chemistry mechanisms such as CAPRAM (see, e.g., Herrmann et al., 2005; Tilgner et al., 2013). Hence, the prediction of the activity coefficients for complex multi-component aerosols, composed of various organic functional groups and electrolytes dissolved in water is the primary purpose of SpactMod. In order to treat various aerosol constituents, additional parameters were included from the mod. LIFAC approach of Kiepe et al. (2006), which can be rewritten in the AIOMFAC formalism (see Appendix A) and incorporated without new parameter fitting. A compilation of the SpactMod parameters is given in Tables A1-A6. The differences to AIOMFAC are highlighted.

\subsubsection{Model treatment of solution non-ideality}

The development of thermodynamic models for mixedsolvent electrolyte systems was an active area of research during the last 3 decades. In general, these models contain several contributions to describe the system non-ideality, which define the excess Gibbs energy $G^{\mathrm{ex}}\left(p, T, n_{j}\right)$ :

$G^{\mathrm{ex}}\left(p, T, n_{j}\right)=G_{\mathrm{LR}}^{\mathrm{ex}}+G_{\mathrm{MR}}^{\mathrm{ex}}+G_{\mathrm{SR}}^{\mathrm{ex}}$,

where $G_{\mathrm{LR}}^{\mathrm{ex}}$ represents the long-range (LR) electrostatic interactions, $G_{\mathrm{SR}}^{\mathrm{ex}}$ is the short-range (SR) contribution resulting from dipole $\leftrightarrow$ dipole and dipole $\leftrightarrow$ induced dipole interactions, and an additional term (middle-range, MR) $G_{\mathrm{MR}}^{\mathrm{ex}}$, which accounts for ionic interactions (e.g., ion $\leftrightarrow$ ion, ion $\leftrightarrow$ dipole, ion $\leftrightarrow$ induced dipole interactions), $p$ is the total pressure, $T$ the absolute temperature, and $n_{j}(j=1, \ldots, N)$ the number of moles of component $j$ in a system. Accordingly, the corresponding activity coefficient $\gamma_{j}^{k}$ of a species $j$ with amount of moles $n_{j}$ in the mixture are derived from expressions for the different parts of $G^{\text {ex }}$ using the relation:

$\ln \gamma_{j}=\left(\frac{\partial G^{\mathrm{ex}} / R T}{\partial n_{j}}\right)_{p, T, n_{j^{\prime} \neq j}}$, 
where $R$ is the universal gas constant. Correspondingly, the activity coefficients are calculated from the aforementioned three different contributions:

$\ln \gamma_{j}=\ln \gamma_{j}^{\mathrm{LR}}+\ln \gamma_{j}^{\mathrm{MR}}+\ln \gamma_{j}^{\mathrm{SR}}$.

\subsubsection{The long-range contribution}

The LR interactions are described as they are in the original AIOMFAC, based on Debye-Hückel theory (Debye and Hückel, 1923). In contrast to other works Li et al. (1994); Yan et al. (1999); Chang and Pankow (2006), AIOMFAC uses the water properties for all solvent components for density and dielectric constant of the solvent mixture, instead of using mixing rules. With this assumption, the corresponding LR activity coefficient expressions for the solvents and ions are defined according to Zuend et al. (2008) as

$$
\begin{aligned}
& \ln \gamma_{s}^{\mathrm{LR},(x)}= \\
& \quad \frac{2 A M_{s}}{b^{3}}\left(1+b \sqrt{I}-\frac{1}{1+b \sqrt{I}}-2 \ln (1+b \sqrt{I})\right), \\
& \ln \gamma_{i}^{\mathrm{LR},(x), \infty}=\frac{-z_{i}^{2} A \sqrt{I}}{1+b \sqrt{I}} .
\end{aligned}
$$

Equation (26) gives the activity coefficient of ion $i$ in the mole fraction basis $(x)$ with the reference state of infinite dilution in water, indicated by super script $\infty$. $M_{S}$ represents the molar mass of solvent $s$ and $z_{i}$ is the number of elementary charges of ion $i$. The ionic strength $I\left(\mathrm{~mol} \mathrm{~kg}^{-1}\right)$ is given as

$$
I=\frac{1}{2} \sum_{i} m_{i} z_{i}^{2}
$$

with the Debye-Hückel parameters

$$
\begin{aligned}
& A=1.327757 \times 10^{5} \cdot{\frac{\sqrt{\rho_{\mathrm{w}}}}{\left(\varepsilon_{\mathrm{w}} T\right)}}^{3 / 2}, \\
& b=6.359696 \cdot \sqrt{\frac{\rho_{\mathrm{w}}}{\left(\varepsilon_{\mathrm{w}} T\right)}} .
\end{aligned}
$$

The Debye-Hückel parameters $A\left(\mathrm{~kg}^{1 / 2} \mathrm{~mol}^{-1 / 2}\right)$ and $b$ $\left(\mathrm{kg}^{1 / 2} \mathrm{~mol}^{-1 / 2}\right)$ depend on temperature $T(\mathrm{~K})$, density $\rho_{\mathrm{w}}$ $\left(\mathrm{kg} \mathrm{m}^{-3}\right)$ and static permittivity $\varepsilon_{\mathrm{W}}\left(\mathrm{C}^{2} \mathrm{~J}^{-1} \mathrm{~m}^{-1}\right)$ of water, calculated based on a distance of closest approach between ions (see Demaret and Gueron, 1993; Antypov and Holm, 2007).

Moreover, this simplification to a water-property-based expression for LR activity coefficients is favorable, due to the uncertainties in estimating unknown dielectric constants of certain organic compounds and maintaining the thermodynamic consistency regarding the selection of reference states (see Raatikainen and Laaksonen, 2005; Zuend et al., 2008). In a real mixture, solvents have densities and dielectric properties different from those of pure water. For this reason, these simplifications of the LR part were made in other mixed solvent models in chemical engineering and technical chemistry applications (see Iliuta et al., 2000). The uncertainties that occurred due to the adopted assumptions to derive the LR and SR activity coefficients with respect to approximations of parameters, were described in the semi-empirical SR part as in the original AIOMFAC (Zuend et al., 2008).

\subsubsection{The middle-range contribution}

The $G_{\mathrm{MR}}^{\mathrm{ex}}$ term is the contribution of the indirect effects of the ionic interactions such as ion $\leftrightarrow$ dipole interactions and ion $\leftrightarrow$ induced dipole interactions to the excess Gibbs energy. For any mixture containing $n_{k},(k=1, \ldots, s)$ moles of solvent $k$ (main groups of organics and water) and $n_{i}$ moles of ion $i, G_{\mathrm{MR}}^{\mathrm{ex}}$ can be expressed as described by Zuend et al. (2008):

$$
\begin{aligned}
\frac{G_{\mathrm{MR}}^{\mathrm{ex}}}{R T} & =\frac{1}{\sum_{k} n_{k} M_{k}} \sum_{k} \sum_{i} B_{k, i}(I) n_{k} n_{i} \\
& +\frac{1}{\sum_{k} n_{k} M_{k}} \sum_{c} \sum_{a} B_{c, a}(I) n_{c} n_{a} \\
& +\frac{1}{\sum_{k} n_{k} M_{k}} \sum_{c} \sum_{a} C_{c, a}(I) n_{c} n_{a} \sum_{i} \frac{n_{i}\left|z_{i}\right|}{\sum_{k} n_{k} M_{k}} \\
& +\frac{1}{\sum_{k} n_{k} M_{k}} \sum_{c} \sum_{c^{\prime} \geq c} R_{c, c^{\prime}}(I) n_{c} n_{c^{\prime}} \\
& +\frac{1}{\left(\sum_{k} n_{k} M_{k}\right)^{2}} \sum_{c} \sum_{c^{\prime} \geq c} \sum_{a} Q_{c, c^{\prime}, a} n_{c} n_{c^{\prime}} n_{a},
\end{aligned}
$$

where $n_{c}$ and $n_{c^{\prime}}$ are the moles of cations, $n_{a}$ are the moles of anions, and $I$ is the ionic strength as defined in Eq. (27). $B_{k, i}(I)\left(\mathrm{kg} \mathrm{mol}^{-1}\right)$ and $B_{c, a}(I)\left(\mathrm{kg} \mathrm{mol}^{-1}\right)$ are ionic strength-dependent binary interaction coefficients between solvent main groups and ions, and between cations and anions, respectively. $C_{c, a}(I)\left(\mathrm{kg}^{2} \mathrm{~mol}^{-2}\right)$ are interaction coefficients between cation $\leftrightarrow$ anion pairs with respect to the total charge concentration. The coefficients $R_{c, c^{\prime}}(I)$ $\left(\mathrm{kg} \mathrm{mol}^{-1}\right)$ and $Q_{c, c^{\prime}, a}(I)\left(\mathrm{kg}^{2} \mathrm{~mol}^{-2}\right)$ are defined as binary and ternary interactions involving two different cations. These binary and ternary interaction coefficients have been introduced in AIOMFAC to improve the description of various ion combinations, specifically at high ionic strength. Hence, these two terms in Eq. (30) can be vanished or neglected in other cases, i.e., for low to moderate ionic strengths.

In the current approach, the MR terms of activity coefficients for the species and organic functional groups described in AIOMFAC are estimated using Eq. (30). As mentioned earlier, the first three interaction coefficients in Eq. (30) are parameterized as functions of ionic strength $I$, which are similar to the ones used for the Pitzer model of Knopf et 
al. (2003):

$$
\begin{aligned}
& B_{k, i}(I)=b_{k, i}^{(1)}+b_{k, i}^{(2)} \exp \left(-b_{k, i}^{(3)} \sqrt{I}\right), \\
& B_{c, a}(I)=b_{c, a}^{(1)}+b_{c, a}^{(2)} \exp \left(-b_{c, a}^{(3)} \sqrt{I}\right), \\
& C_{\mathrm{c}, \mathrm{a}}(I)=c_{c, a}^{(1)} \exp \left(-c_{\mathrm{c}, \mathrm{a}}^{(2)} \sqrt{I}\right)
\end{aligned}
$$

where $b_{k, i}^{(1)}, b_{k, i}^{(2)}, b_{c, a}^{(1)}, b_{c, a}^{(2)}, c_{c, a}^{(1)}$ and $c_{c, a}^{(2)}$ are adjustable parameters, which are determined by fitting AIOMFAC activity coefficients to experimental data sets (see Zuend et al., 2008, for further details). The parameter $b_{c, a}^{(3)}$ was used mostly to describe aqueous salt solutions assuming a fixed value of $0.8 \mathrm{~kg}^{1 / 2} \mathrm{~mol}^{1 / 2}$. Similarly, we have considered the same value for the ions when the activity coefficients are estimated from AIOMFAC. Furthermore, Zuend et al. (2008) argued that, for such cases, where this value did not result in a satisfactory data fit, $b_{c, a}^{(3)}$ are allowed to vary. On the other hand, the parameter $b_{k, i}^{(3)}$ was fixed for all mixed organicinorganic solutions assuming a value of $1.2 \mathrm{~kg}^{1 / 2} \mathrm{~mol}^{1 / 2}$. All interaction coefficients in the MR part are symmetric $B_{c, a}(I)=B_{a, c}(I)$. Subsequently, water is defined as the reference solvent for inorganic ions, no explicit ion $\leftrightarrow$ water interactions are determined, i.e., $B_{k=\mathrm{H}_{2} \mathrm{O}, i}(I)$ is prescribed as zero for all inorganic ions. However, the effects of solution non-ideality from cations and anions interacting with water molecules are indirectly accounted for via the cation $\leftrightarrow$ anion interaction coefficients, $B_{c, a}(I), C_{c, a}(I), R_{c, c^{\prime}}$ and $Q_{c, c^{\prime}, a}$ as the corresponding interaction parameters, which were determined on the basis of (organic-free) aqueous electrolyte solutions.

As depicted earlier, the MR interaction parameters in AIOMFAC were fitted for limited organic compounds (i.e., alkyl and hydroxyl) and ions. Contrarily, interaction parameters were not evenly available for overall systems of current interest, i.e., to treat the organic compounds and ions involved in multiphase mechanisms such as CAPRAM. Hence, in this study, the ion $\leftrightarrow$ ion and organic main group $\leftrightarrow$ ion interaction parameter database is extended by incorporating parameters of the modified LIFAC approach of Kiepe et al. (2006). The complete procedure of the extension of model interaction parameters is explained in Appendix A.

\subsubsection{The short-range contribution}

The SR contribution $\ln \gamma_{\mathrm{SR}}^{\mathrm{ex}}$ to the total Gibbs excess energy in SpactMod is represented by the modified group-contribution method UNIFAC (Fredenslund et al., 1975), as performed by Zuend et al. (2008). AIOMFAC incorporates the revised parameter set of Hansen et al. (1991) (standard UNIFAC) for most of the functional group interactions. Besides, these modifications include the insertion of further inorganic ions to account for their effects on the thermodynamic properties such as entropy and enthalpy of mixing apart from their charge-related interactions (Li et al., 1994; Yan et al., 1999;
Zuend et al., 2008). AIOMFAC utilizes the specific UNIFAC parameterizations of Marcolli and Peter (2005) for hydroxyl and alkyl functional groups.

Similar to the addition of interaction parameters derived for the MR part, the same functional groups are also included in the SR part, while maintaining the compatibility with the mathematical model expressions proposed in AIOMFAC. As Zuend et al. (2008), we used the UNIFAC parameterizations of Marcolli and Peter (2005), which are adopted from Hansen et al. (1991). Additionally, the revised parameterizations for the functional group $\mathrm{COOH}$ are taken from Peng et al. (2001), which differs from the parameter matrix proposed in standard UNIFAC by Hansen et al. (1991). Since the same mathematical formulations are used in these models and differs only in main group interaction parameters, the parameter matrix is compatible to use. The influence of estimated activity coefficients when merging specific parameters from the distinctive UNIFAC parameterizations within SpactMod has been tested. Sensitivity studies have shown that SpactMod predicts relatively better results when combining the main functional group interaction parameters instead of using the standard UNIFAC parameter set only (see Sect. 3.2). The interaction parameters for these organic functional groups are shown in Appendix B.

In UNIFAC, the activity coefficient $\gamma_{j}$ of a molecular component $j$ ( $j$ can be used for solute or solvent) in a multicomponent mixture is in general expressed as the summation of contributions of (i) a combinatorial part $(C)$ accounting for the geometrical properties of the molecule and (ii) a residual part $(R)$, which results from inter-molecular interactions:

$\ln \gamma_{j}^{\mathrm{SR}}=\ln \gamma_{j}^{C}+\ln \gamma_{j}^{R}$.

Since ions are treated as solvent components in the SR terms, resulting activity coefficients in Eq. (34) are with respect to the symmetrical convention on a mole fraction basis. For ions, the unsymmetrical normalized activity coefficient is determined from

$\ln \gamma_{i}^{\mathrm{SR},(x), \infty}=\ln \gamma_{i}^{\mathrm{SR},(x)}+\ln \gamma_{i}^{\mathrm{SR},(x), \text { ref }}$.

The symmetrically normalized value at the reference state is computed from the combinatorial and residual parts, by introducing the reference state conditions of the ions (setting $x_{\mathrm{w}}=1, \sum_{s} x_{s}=0$ for $s \neq w$ and $\sum_{i} x_{i}=0$ ):

$$
\begin{aligned}
\ln \gamma_{i}^{\mathrm{SR},(x), \text { ref }} & =\ln \frac{r_{i}}{r_{\mathrm{w}}}+1-\frac{r_{i}}{r_{\mathrm{w}}} \\
& +\frac{z}{2} q_{i}\left[\ln \left(\frac{r_{\mathrm{w}} q_{i}}{r_{i} q_{\mathrm{w}}}\right)-1+\frac{r_{\mathrm{w}} q_{i}}{r_{i} q_{\mathrm{w}}}\right] \\
& +q_{i}\left(1-\ln \psi_{\mathrm{w}, i}-\psi_{i, \mathrm{w}}\right),
\end{aligned}
$$




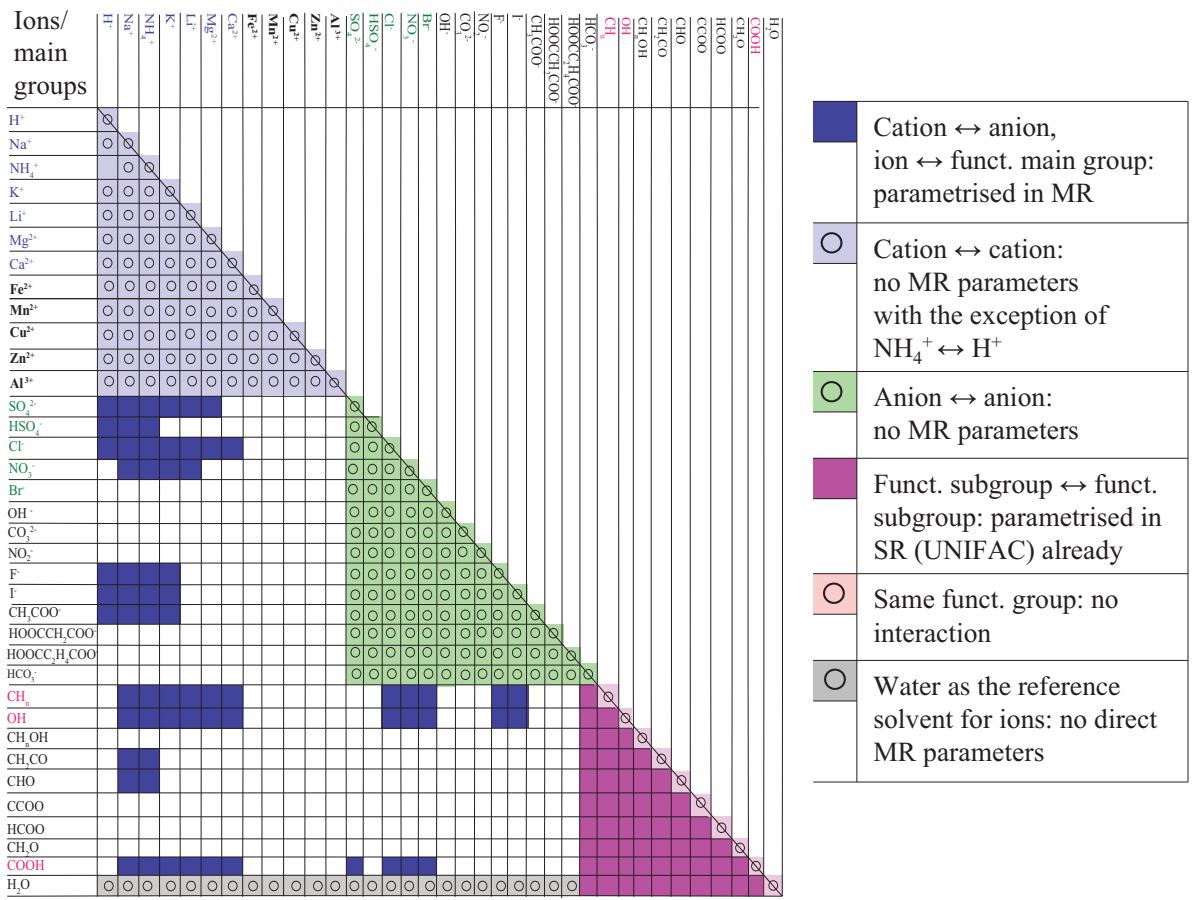

Figure 4. Scheme of the currently used interactions in the MR and SR parts. Parameters for ion $\leftrightarrow$ ion and ion $\leftrightarrow$ organic main group interactions are all incorporated in the MR part and set to zero in the SR (UNIFAC) part.

where subscript $\mathrm{w}$ stands for the reference solvent (water). The parameters $q_{i}$ and $r_{i}$ represent the surface area and the volume, respectively, of component $i$. The last term on the right-hand side of Eq. (36) reflects the residual part reference contribution and becomes zero as we defined the SR ion $\leftrightarrow$ solvent interactions to be zero. Figure 4 shows the binary species combinations, for which the specific parameters have been used in this study. Mean interactions between ions and water are indirectly represented by the parameters of the cation $\leftrightarrow$ anion interaction pairs according to Zuend et al. (2008), since the aqueous solution is defined as the reference system similar to the assumption used in conventional Pitzer models (Pitzer, 1991). The relative van der Waals subgroup volume and surface area parameters, $R_{t}$ and $Q_{t}$, account for pure component properties. At the same time, $R_{t}$ and $Q_{t}$ values for the ions can be estimated from the ionic radii. In order to maintain the compatibility with the model equations of AIOMFAC, the hydrated group volume and surface area parameters $R_{t}^{\mathrm{H}}$ and $Q_{t}^{\mathrm{H}}$ are calculated using an empirical parameterization given by Achard et al. (1994). For those ions, the activity coefficients are estimated using the mod. LIFAC approach. Likewise, the database is extended for other ions in order to estimate the activity coefficients from the SR part. The measured apparent dynamic hydration numbers $\left(N_{t}^{\mathrm{ADH}}\right)$ data are adopted from Kiriukhin and Collins (2002) to estimate the final values $R_{t}^{\mathrm{H}}$ and $Q_{t}^{\mathrm{H}}$ instead of $R_{t}$ and $Q_{t} . R_{t}^{\mathrm{H}}$ and $Q_{t}^{\mathrm{H}}$ are computed consistently in the model equations (see Table A2 in the Appendix) by

$R_{t}^{\mathrm{H}}=R_{t}+N_{t}^{\mathrm{ADH}} \cdot R_{\mathrm{w}}$,
$Q_{t}^{\mathrm{H}}=Q_{t}+N_{t}^{\mathrm{ADH}} \cdot Q_{\mathrm{w}}$,

where $R_{\mathrm{w}}$ and $Q_{\mathrm{w}}$ refer to the values of the water molecule and $N_{t}^{\mathrm{ADH}}$ are measured apparent dynamic hydration numbers at $303.15 \mathrm{~K}$ (Kiriukhin and Collins, 2002). As shown in Fig. 4, the interactions of the ions $\mathrm{Mg}^{2+}, \mathrm{Ca}^{2+}, \mathrm{F}^{-}, \mathrm{I}^{-}, \mathrm{OH}^{-}$, $\mathrm{NO}_{2}^{-}, \mathrm{CO}_{3}^{-}$and $\mathrm{CH}_{3} \mathrm{COO}^{-}$are implemented from Kiepe et al. (2006). Due to the increasing interest in remaining ions included in the CAPRAM multiphase mechanism (e.g., $\mathrm{Fe}^{2+}$, succinate, and malonate), the activity coefficients are computed while prescribing the corresponding interaction parameters as zero.

\subsubsection{Total activity coefficients}

Finally, SPACCIM's activity coefficient module (SpactMod) estimates the total activity coefficients for each species according to the Gibbs energy (cp. Eqs. 22 and 24). Then, the activity coefficient of a solvent species $s$ is determined by $\mathrm{Li}$ et al. (1994); Yan et al. (1999); Kiepe et al. (2006); Zuend et al. (2008)

$\ln \gamma_{s}^{(x)}=\ln \gamma_{s}^{\mathrm{LR},(x)}+\ln \gamma_{s}^{\mathrm{MR},(x)}+\ln \gamma_{s}^{\mathrm{SR},(x)}$

Accordingly, the complete expression for the ions, with regard to the unsymmetrical convention on molality basis at which the standard state is the hypothetical ideal solution of 
unit molality at system pressure and temperature, can be written as follows:

$$
\begin{aligned}
\ln \gamma_{i}^{(m)} & =\left[\ln \gamma_{i}^{\mathrm{LR},(x), \infty}+\ln \gamma_{i}^{\mathrm{MR},(x), \infty}+\ln \gamma_{i}^{\mathrm{SR},(x), \infty}\right] \\
& -\ln \left[\frac{M_{\mathrm{w}}}{\sum_{s} x_{s}^{*} M_{S}}\right]+M_{\mathrm{w}} \sum_{i^{\prime}} m_{i^{\prime}}
\end{aligned}
$$

where $M_{s}$ is the molar mass of solvent component $s, x_{s}^{*}$ its salt-free mole fraction, and $m_{i^{\prime}}$, is the molality of ion $i^{\prime}$. The last term on the right-hand side of Eq. (40) converts the activity coefficient $\ln \gamma_{s}^{(x)}$ (infinitely diluted reference state on the mole fraction basis) to the activity coefficient on molality basis and infinitely diluted (in water) reference state. One can derive this term based on convention independence of the chemical potentials $\left(\mu_{i}^{(m)}\left(p, T, n_{j}\right)=\mu_{i}^{(x)}\left(p, T, n_{j}\right)\right)$ and the definitions of the chosen reference states (Zuend et al., 2008).

The extension of the database by the combination of AIOMFAC and modified LIFAC makes SPACCIM a versatile tool to study the influence of the treatment of solution non-ideality on multiphase aerosol chemistry. SpactMod is highly flexible to extension and further inclusion of organic functional groups and ions, whenever the required data become available. During the implementation of the code, the activity coefficients responsible for LR and SR contribution terms are computed for all the ions (either cation or anion) included in the considered chemical system. For those species, where the interaction parameters are not available to compute MR contribution terms; they are prescribed as unity (i.e., $\left.\gamma_{i}^{\mathrm{MR},(x), \infty}=1\right)$ due to the lack of an extensive database.

\section{Model evaluation and applications}

In this section we will examine the model extensions described above. Especially, the SpactMod activity coefficient module is evaluated and compared with literature data. The reliability of the extended SPACCIM code is shown in the last subsection. Furthermore, the deviation of the activity coefficients from ideality and, consequently, the impact on the chemical behavior are demonstrated for a test scenario. A more detailed analysis of the impact of the non-ideality approach on the multiphase will be published in a separate paper.

\subsection{Evaluation of the activity coefficient module}

Considerable effort has been devoted by several authors (see, e.g., Raatikainen and Laaksonen, 2005; Tong et al., 2008; Zuend et al., 2008) to compare different established activity coefficient models that could be potentially suitable for modeling of hygroscopic properties of organic-electrolyte particles as well as the prediction of activity coefficients of aqueous species. The investigations summarized here were aimed

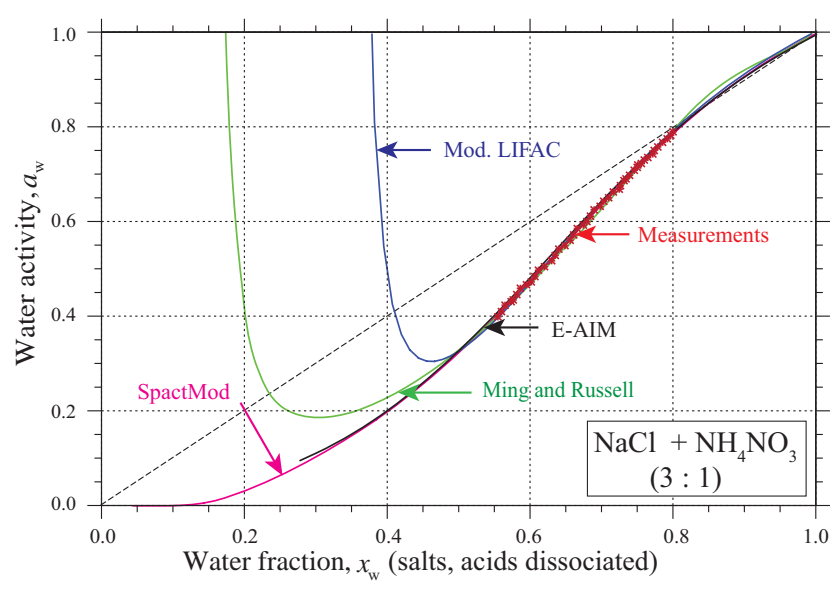

Figure 5. Comparison with measurements of aqueous electrolyte solutions (symbols) and corresponding calculations of the models E-AIM/AIM III (Clegg et al., 1998b), mod. LIFAC (Kiepe et al., 2006), Ming and Russell (Ming and Russell, 2002) and SpactMod at $298 \mathrm{~K}$ for the salt $\mathrm{NaCl}+\mathrm{NH}_{4} \mathrm{NO}_{3}$ at a molar salt mixing ratio of $(3: 1)$. Note that SpactMod reproduces the results of AIOMFAC (Zuend et al., 2008) due to the same parameters applied.

at evaluating the robustness of the SpactMod implemented module and at checking the reproducibility towards original model results. However, the interaction parameters in the applied models were fitted against measurements. Hence, this comparison can be considered as an indirect comparison with measurements. Furthermore, results are also compared with direct water activity measurements and the AIM (Aerosol Inorganic Model) of Clegg et al. (1998b, a). The model comparisons cover a scale ranging from very simple to complex simulations. Initially, the comparison is performed for selected binary aqueous electrolyte solutions, then aqueous organic solutions, followed by mixtures of aqueous organicelectrolyte solutions. However, here we present the results of selected examples only.

\subsubsection{Comparison between activity coefficient models for inorganic systems}

Naturally, the reproducibility of the original AIOMFAC results in Zuend et al. (2008) was verified in a first step. Note that the graphs of the newly implemented SpactMod module depicted in Figs. 5 and 6 correspond to the original results given in Zuend et al. (2008). Figure 5 shows the comparison between calculated water activities predicted by the selected four models and experimental data. The differences for the electrolyte mixture of $\mathrm{NaCl}+\mathrm{NH}_{4} \mathrm{NO}_{3}$ are in good agreement up to moderate salt concentrations $\left(x_{\mathrm{w}} \geq 0.5\right)$. The values for high concentrations $\left(x_{\mathrm{w}} \leq 0.4\right)$ indicate the formation of a solid salt (or hydrate), when the solution becomes supersaturated as well as the deliquescent point of the particular salt. The models do not reproduce this, since the formation of solids was not incorporated in the present model 


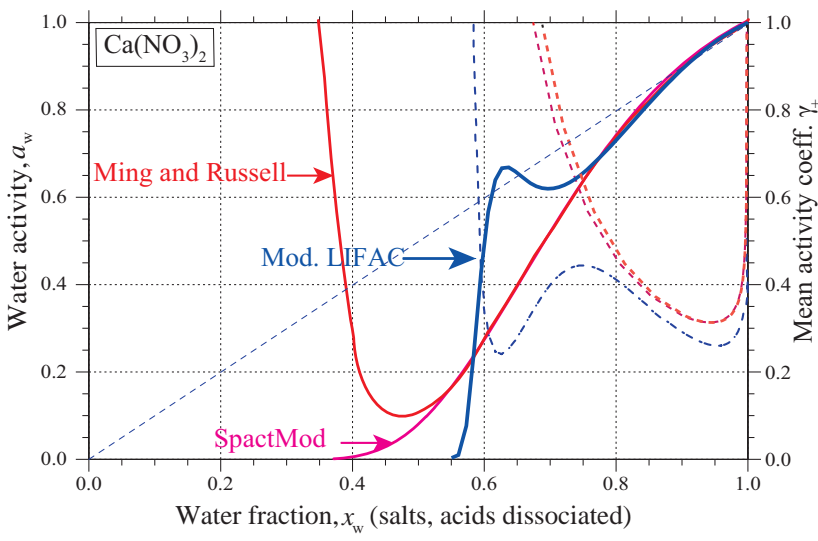

Figure 6. Intercomparison between selected models for $\mathrm{Ca}\left(\mathrm{NO}_{3}\right)_{2}$ salt: Water activities (solid lines) and mean activity coefficients (dashed lines). Again, SpactMod reproduces AIOMFAC.

calculations. As can be seen from Figs. 5 and 6, the modeled water activities agree well with each other at low concentrations. Contrarily, at high salt concentrations, mod. LIFAC strongly deviates from SpactMod as shown in Fig. 5, by a steep increase in $a_{\mathrm{w}}$ and in Fig. 6 by an increase followed by a sharp decrease, as shown by Zuend et al. (2008). Note that the $\mathrm{Ca}\left(\mathrm{NO}_{3}\right)_{2}$ parameterization of mod. LIFAC (see Fig. 6) results only from water activity data of bulk measurements as the approach of the Ming and Russell (2002) model behaves similarly to SpactMod at medium concentrations and proceeds to formation of solids. The interaction coefficients of AIOMFAC applied in SpactMod were fitted from vaporliquid as well as liquid-liquid equilibrium data, salt solubilities and electromotive force measurements covering also high solution concentrations and ternary mixtures (Zuend et al., 2008). Hence, the slope of the curve enables much better descriptions and predictions up to high concentrations, even very low water concentration available and at high ionic strength. It is noted that $\mathrm{Ca}\left(\mathrm{NO}_{3}\right)_{2}$ is not available in the AIM, thus Fig. 6 includes only results of the other activity coefficient approaches.

Apart from the predicted water activities, the calculated mean activity coefficients also have differences with each other. Therefore, a comparison of mean activity coefficients is presented additionally in Fig. 6 . The mean activity coefficient $\left(\gamma_{ \pm}\right)$is related to single ion-activity coefficients by

$\gamma_{ \pm}=\left(\gamma_{+}^{V_{+}} \cdot \gamma_{-}^{V_{-}}\right)^{1 /\left(V_{+}+V_{-}\right)}$

where $\gamma_{+}$and $\gamma_{-}$are the activity coefficients of a cation and anion, respectively. $V_{+}$and $V_{-}$are the corresponding stoichiometric coefficients. The mean activity coefficients predicted by AIOMFAC and the approach of Ming and Russell (2002) show a similar curve shape with $5 \%$ of difference. In contrast, mod. LIFAC shows a different behavior especially for water fractions later than 0.8 .

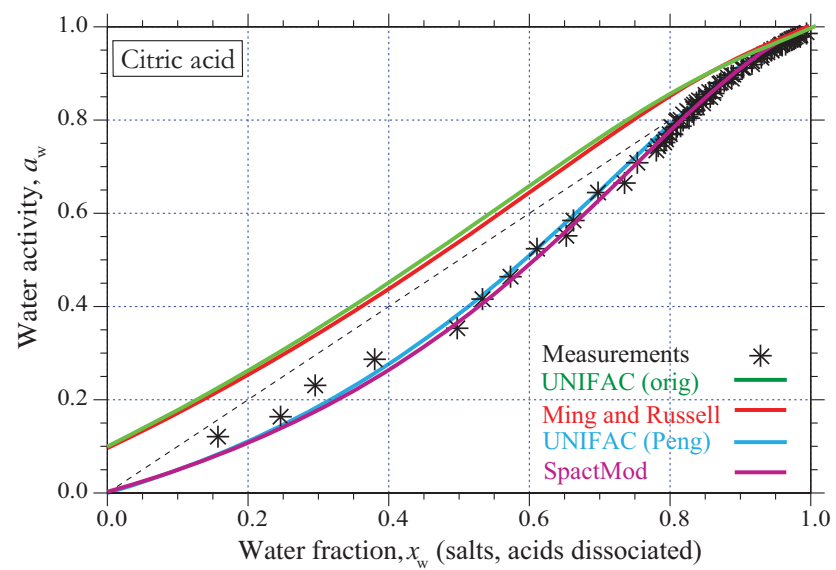

Figure 7. Comparison between experimental and calculated water activities $\left(a_{\mathrm{W}}\right)$ in aqueous citric acid solutions as a function of water fraction $\left(x_{\mathrm{W}}\right)$ at $298.15 \mathrm{~K}$. Experimental data are taken from Maffia and Meirelles (2001).

\subsubsection{Verification of SpactMod for organic-electrolyte mixtures}

In this section, the performance of different activity coefficient models is evaluated by comparing calculated and measured water activities of mixtures of electrolyte and organic system. For all water activity calculations, the organic acids are treated as non-dissociating solutes, and a single liquid phase is assumed with no solid phases present. All calculations are performed at atmospheric pressure (1 atm) and at $298 \mathrm{~K}$.

Figure 7 shows the comparison of experimental data with predicted water activities using different UNIFAC parameterizations. Here, the parameters for the original UNIFAC are adopted from Hansen et al. (1991). Furthermore, a revised set of fitted UNIFAC parameters given by Peng et al. (2001) for the interactions of functional groups $\mathrm{OH}, \mathrm{H}_{2} \mathrm{O}$ and $\mathrm{COOH}$ is used for the comparison. As depicted in Fig. 7, the original UNIFAC and Ming and Russell (2002) exhibit similar behavior for all water fractions. Moreover, SpactMod and the version of Peng et al. (2001) have deviations that are usually less than $50 \%$ of the deviations with the original UNIFAC. Furthermore, the original UNIFAC exhibits much bigger deviations than the UNIFAC version of Peng et al. (2001) and SpactMod. The last two models show a similar behavior and a good agreement with the measurements. In difference to the Peng approach, SpactMod take into account dynamic hydration numbers (see Eqs. 37 and 39), which is in consistency with the computation of the combinatorial term in AIOMFAC.

Figure 8 shows the comparison of mean ionic activity coefficients of binary electrolyte mixtures. As can be seen from the plot, good results were obtained by SpactMod based on mod. LIFAC parameterization. Mod. LIFAC shows better results compared to LIFAC due to the improved reference state 


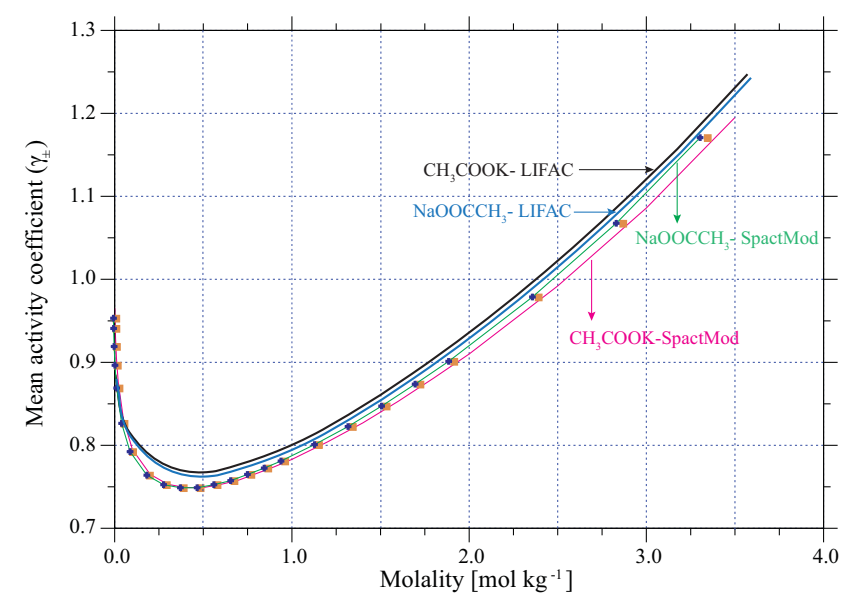

Figure 8. Comparison between experimental (symbols) and calculated mean activity coefficients (solid lines) of binary salt mixtures as a function of molality $\left(\mathrm{mol} \mathrm{kg}^{-1}\right)$ at $298 \mathrm{~K}$. Experimental data are taken from Hamer and $\mathrm{Wu}(1972)$.

calculation of ions in the SR part. Due to the normalization of ions, SpactMod gives better agreement compared to original LIFAC for these binary electrolytes.

Figure 9 shows the comparison between predicted water activities from different activity coefficient models for the mixture of $\left(\mathrm{NH}_{4}\right)_{2} \mathrm{SO}_{4}+$ glycerol $+\mathrm{H}_{2} \mathrm{O}[(2: 1: 1)$ mole ratio]. As expected, SpactMod accurately reproduces the results from the original AIOMFAC. All the models behave similarly up to moderate concentrations $\left(x_{\mathrm{w}}=0.6\right)$. As in Fig. 6, at lower water activity, mod. LIFAC and LIFAC strongly deviate from SpactMod. As argued earlier, LIFAC and mod. LIFAC are able to predict vapor liquid equilibria and liquid liquid equilibria, but cannot describe the deviations from ideality at high concentrations. A steep increase in $a_{\mathrm{w}}$ shown in Fig. 9 has to be rated as artifacts of the LIFAC and mod. LIFAC parameterization.

Figure 10 shows the comparison between experimental and predicted water activities for the mixture of $\left(\mathrm{NH}_{4}\right)_{2} \mathrm{SO}_{4}+$ ethanol + acetic acid [(2:1:1) mole ratio]. All the models strongly agree with the measurements at high relative humidities or at low and moderate salt concentrations $\left(x_{\mathrm{w}} \approx 0.8\right)$. However, at the deliquescent phase $\left(x_{\mathrm{w}} \approx 0.6\right)$, the mod. LIFAC and Ming and Russell (2002) model strongly deviate from SpactMod. These differences for lower water fractions are mainly caused by the different treatment of ion $\leftrightarrow$ organic interactions included in the models. It can be seen from Fig. 10 that the strange behavior does not appear for the pure organic and pure electrolyte mixture predictions. The MR interaction term in the model is responsible for this atypical shape in the predictions. Moreover, Raatikainen and Laaksonen (2005) argued that, in the MR part, the logarithms of activity coefficients are calculated as sums of terms, which are proportional to the fitting parameters, ion molalities and ionic strength. Because these terms have quite large numeri-

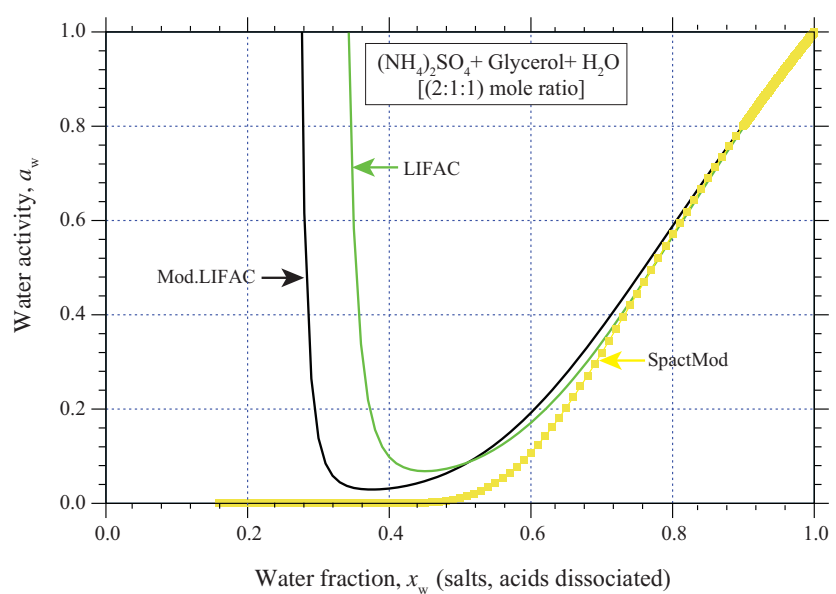

Figure 9. Comparison of modeled water activities for the aqueous solution composed of an organic-electrolyte mixture: $\left(\mathrm{NH}_{4}\right)_{2} \mathrm{SO}_{4}+$ glycerol $+\mathrm{H}_{2} \mathrm{O}[(2: 1: 1)$ mole ratio]. The SpactMod results are in agreement with AIOMFAC.

cal values, and a small change in the interaction parameters or molality can cause a very big change to activity coefficients. The MR part and modification of SR part given in SpactMod could be the main reason, since this model can predict the water activities at high salt concentrations as well. Consequently, as can be seen from Fig. 10, mod. LIFAC have an increase followed by a sharp decrease, features that have to be rated as artifacts of the mod. LIFAC parameterization, whereas the Ming and Russell (2002) model has also a strong increase after the water fraction is about $\left(x_{\mathrm{w}} \approx 0.3\right)$. As mentioned earlier, these artifacts indicate the formation of a solid salt (or hydrate), when the solution becomes supersaturated, since the formation of solids was not enabled in the model calculations.

However, the consideration here is only a limited set of mixtures of organic-electrolyte compounds. Hence, the presented results should be viewed as a first assessment. The scarcity of experimental data for mixtures of atmospheric relevance remains a limitation for testing activity coefficient models. When experimental data become available in the future, the models can be validated against measurements while comparing the water activity and species activity coefficients against water fraction $x_{\mathrm{w}}$. All in all, despite the difficulties in determining the ion $\leftrightarrow$ organic mixture parameters, it should be noted that the ion $\leftrightarrow$ organic interaction parameters have improved the model performance, a fact that was already noted in previous studies (Clegg et al., 1998a, b, 2001; Tong et al., 2008).

\subsection{Sensitivity studies on the importance of the different interactions}

Tong et al. (2008) studied the importance of inclusion of a treatment of ion $\leftrightarrow$ organic interactions and state that these 


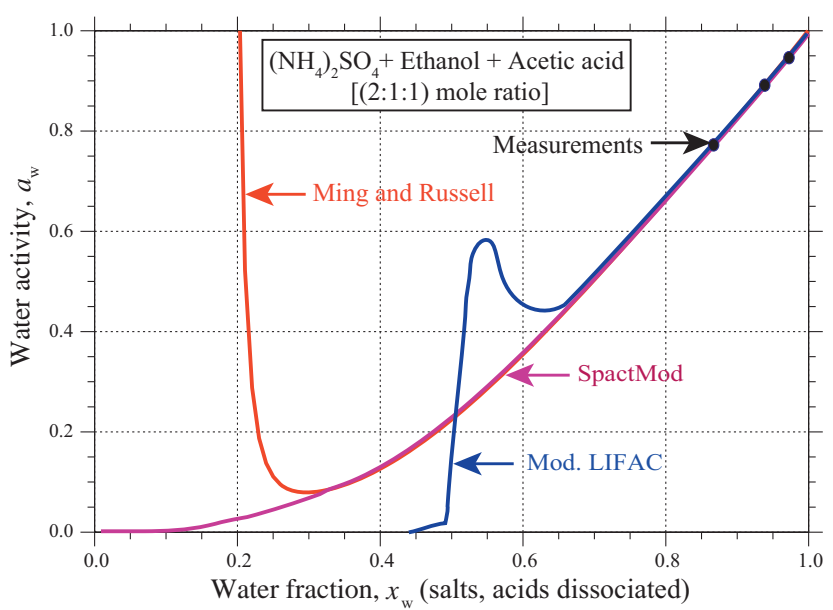

Figure 10. Comparison between measured and modeled water activities for the aqueous solution composed of organic-electrolyte mixture: $\left(\mathrm{NH}_{4}\right)_{2} \mathrm{SO}_{4}+$ ethanol + acetic acid [(2:1:1) mole ratio].

interactions would substantially improve the performance of the coupled models over that of the decoupled models. It has been concluded that decoupled approaches, such as those in CSB (Clegg et al., 2001) and ADDEM (Topping et al., 2005a, b), perform well, and in some cases better, than the coupled models (Ming and Russell, 2002; Erdakos et al., 2006). Additionally, in such cases, the ion $\leftrightarrow$ organic terms do not necessarily lead to improved model predictions. At the same time, models are a prerequisite, composed of an aqueous electrolyte term, an (aqueous) organic term, and an organic $\leftrightarrow$ ion mixing term in order to treat the organic-inorganic mixtures. In contrast to the study of Tong et al. (2008), the present study aims at the evaluation of the importance of different interaction terms in the model approach Eq. (24) for the computation of water activities and the activity coefficients.

Intermolecular forces or interactions are essential in the deliquesced particle phase, where high solute concentrations and low water fractions are available. They are important because they are responsible for many of the physical properties of solids, liquids, and gases. Moreover, these interaction forces become significant at the molecular range of about $1 \mathrm{~nm}$ or less, but are much weaker than the forces associated with chemical bonding. The characteristic contribution of different interaction forces from the model development point of view in the solution can be computed using Eq. (24). Utilizing this conceptual idea in the computation of activity coefficients, here we address the question, which intermolecular forces of attraction are important and need be considered for the treatment of solution non-ideality for organicelectrolyte mixtures. In order to answer this question, the SpactMod is used for sensitivity studies. Overall, the studies have revealed that middle-range (MR) interactions are important to compute the total activity coefficients.

Figure 11 shows the contribution of different interaction forces in the solution for the mixture of

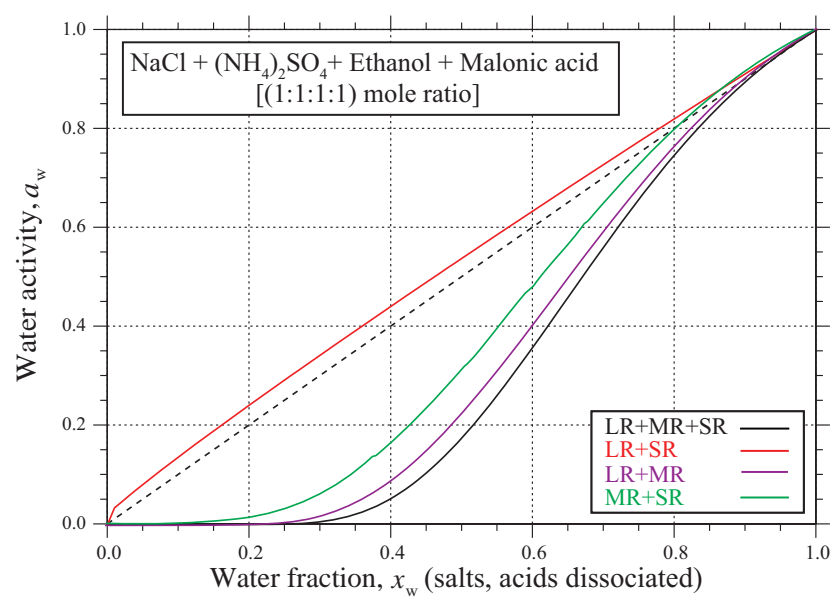

Figure 11. Importance of different interactions in the aqueous solution composed of $\mathrm{NaCl}+\left(\mathrm{NH}_{4}\right)_{2} \mathrm{SO}_{4}+$ ethanol + malonic acid $[1: 1: 1: 1$ (mole ratio)].

$\mathrm{NaCl}+\left(\mathrm{NH}_{4}\right)_{2} \mathrm{SO}_{4}+$ ethanol + malonic acid $\quad[1: 1: 1: 1$ (mole ratio)] as an example. However, the deviations regarding the different interactions depend on the considered mixture. As can be seen in Fig. 9, the water activity strongly deviates in the absence of MR interaction forces, mainly caused from ion $\leftrightarrow$ ion, ion $\leftrightarrow$ dipole and ion $\leftrightarrow$ induced dipole forces. Thus, the MR interactions were found to be important. Similar to the findings of Tong et al. (2008), it is expected that ion $\leftrightarrow$ organic interactions will be of most importance in solutions with high solute concentrations, for which inclusion of ion $\leftrightarrow$ organic parameters would be beneficial. However, the absence of each interaction term can be seen in Fig. 11. The short-range interactions also influence in the total contribution of computation of water activity, where the deviations are about $10 \%$. In the case of the considered MR and SR interactions, the deviations are about $25 \%$. It should be noted that the ion $\leftrightarrow$ organic interactions are the dominant interaction forces in the solution; however, the further interaction forces need to be considered. The deviations from the total contribution of interaction forces is significant in all ranges of relative humidity as well as in the full range of concentration. Nevertheless, the deviations are increasing from a lower salt-acid concentration to higher. During the low salt-acid concentration $\left(x_{\mathrm{w}} \approx 0.9\right)$, the contribution of the considered interactions were found to be similar.

\subsection{First application of the advanced SPACCIM}

To demonstrate the functioning of the whole advanced SPACCIM framework, including the newly considered SpactMod activity coefficient module and a complex multiphase aerosol chemistry mechanism, first air parcel simulations have been performed with a simple model scenario. In the two following subsections, the applied model sce- 

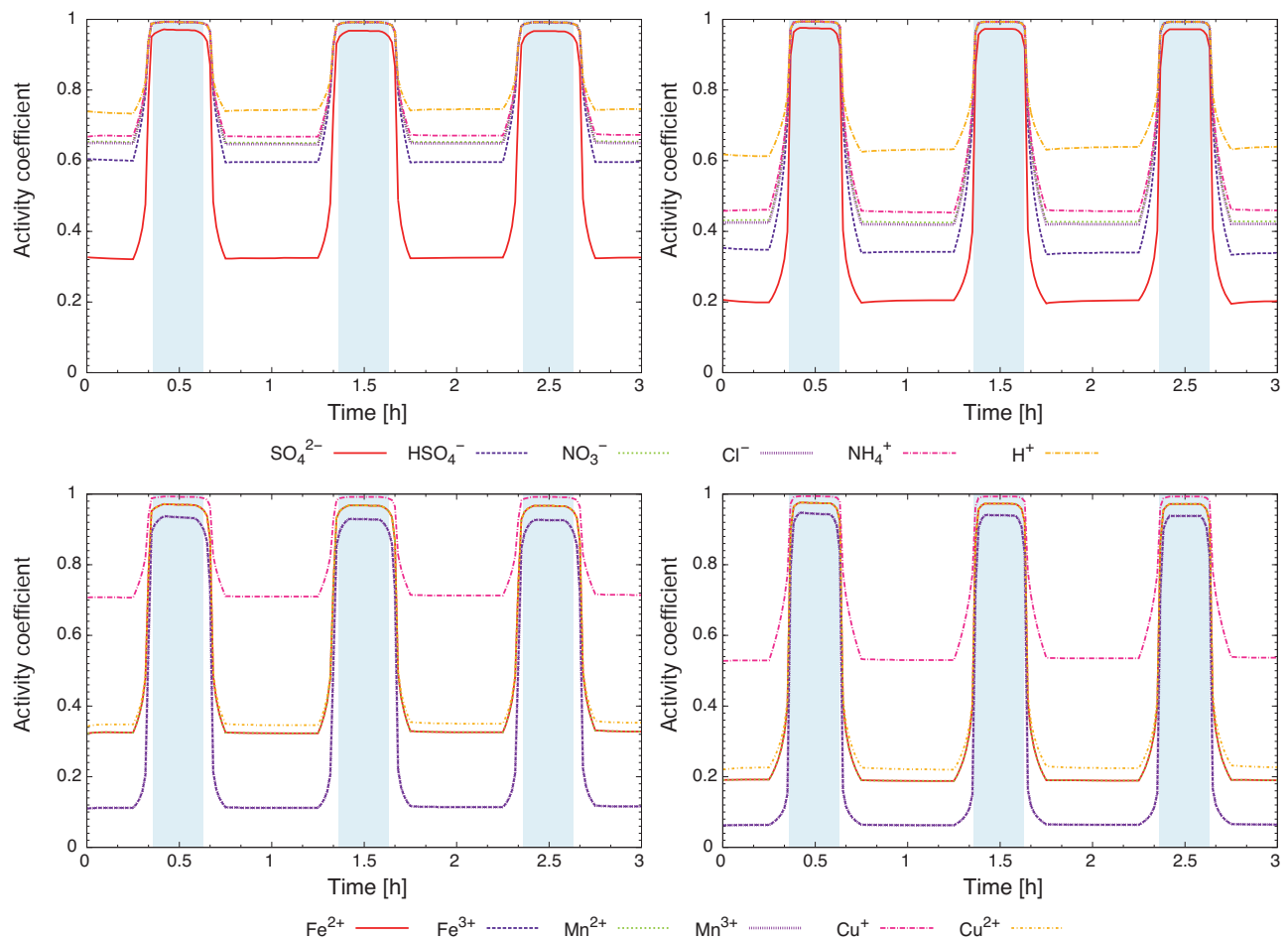

Figure 12. Modeled activity coefficients of main inorganic particle-phase constituents (top) and important transition metal ions (TMIs, down) as the function of the simulation time for the two different relative humidity cases (left: $90 \% \mathrm{RH}$; right: $70 \% \mathrm{RH}$ ). The blue bars mark the in-cloud time periods during the simulation time.

nario and chemical mechanism is briefly outlined, and subsequently selected model results are presented. However, it is noted that the presented simulations are not aimed at the detailed examination of non-ideal solution effects on multiphase chemical processes. The detailed investigation of this complex issue will be given in a companion paper (Rusumdar et al., 2016).

\subsubsection{Model scenario and chemical mechanism}

In the applied meteorological scenario, an air parcel moves along a predefined $3 \mathrm{~h}$ model trajectory that involves three cloud passages and non-cloud periods in which the aerosol particles are deliquesced. Simulations were performed with and without consideration of non-ideal solutions. Furthermore, the simulations have been performed with two different relative humidity levels ( 90 and $70 \% \mathrm{RH}$ ) during the noncloud periods. In total, simulations have been performed for four cases: with and without consideration of non-ideal solutions and both with 90 and $70 \%$ relative humidity levels during the non-cloud periods, respectively. For the modeling, mono-disperse aerosol particles with a radius of $200 \mathrm{~nm}$ and a number concentration of $1.0 \times 10^{+8} \mathrm{~cm}^{-3}$ were used.

For the test simulations, a complex multiphase chemistry mechanism has been applied. The applied mechanism consists of the RACM-MIM2ext gas-phase mechanism (Tilgner and Herrmann, 2010) and an extended version of the CAPRAM2.4 aqueous-phase mechanism (CAPRAM2.4 + organicExt). The employed aqueous-phase mechanism consists of the CAPRAM2.4 mechanism (Ervens et al., 2003) combined with the reduced organic extension of CAPRAM3.0i-red (Deguillaume et al., 2010) along with the condensed oxidation scheme of malonic acid and succinic acid based on the CAPRAM3.0i-red (see Deguillaume et al., 2010, for further details). Thus, the aqueous-phase mechanism contains a detailed oxidation scheme of inorganic as well as organic compounds with 204 species and 477 reactions. The considered organic reaction scheme describes the chemistry of organic compounds with up to four carbon atoms and different functional groups. All model simulations have been performed for continental remote environmental conditions (see Ervens et al., 2003, for further details).

\subsubsection{Model results}

\section{Modeled activity coefficients of key inorganic ions}

Figure 12 depicts the time evolution of the activity coefficients of main inorganic ions and key transition metal ions (TMIs) modeled for the two different relative humidity cases. The plots show, expectedly, a strong dependency on the microphysical conditions. During cloud conditions, the modeled activity coefficients are almost equal to unity for the depicted ions. The in-cloud activity coefficients of ions with 

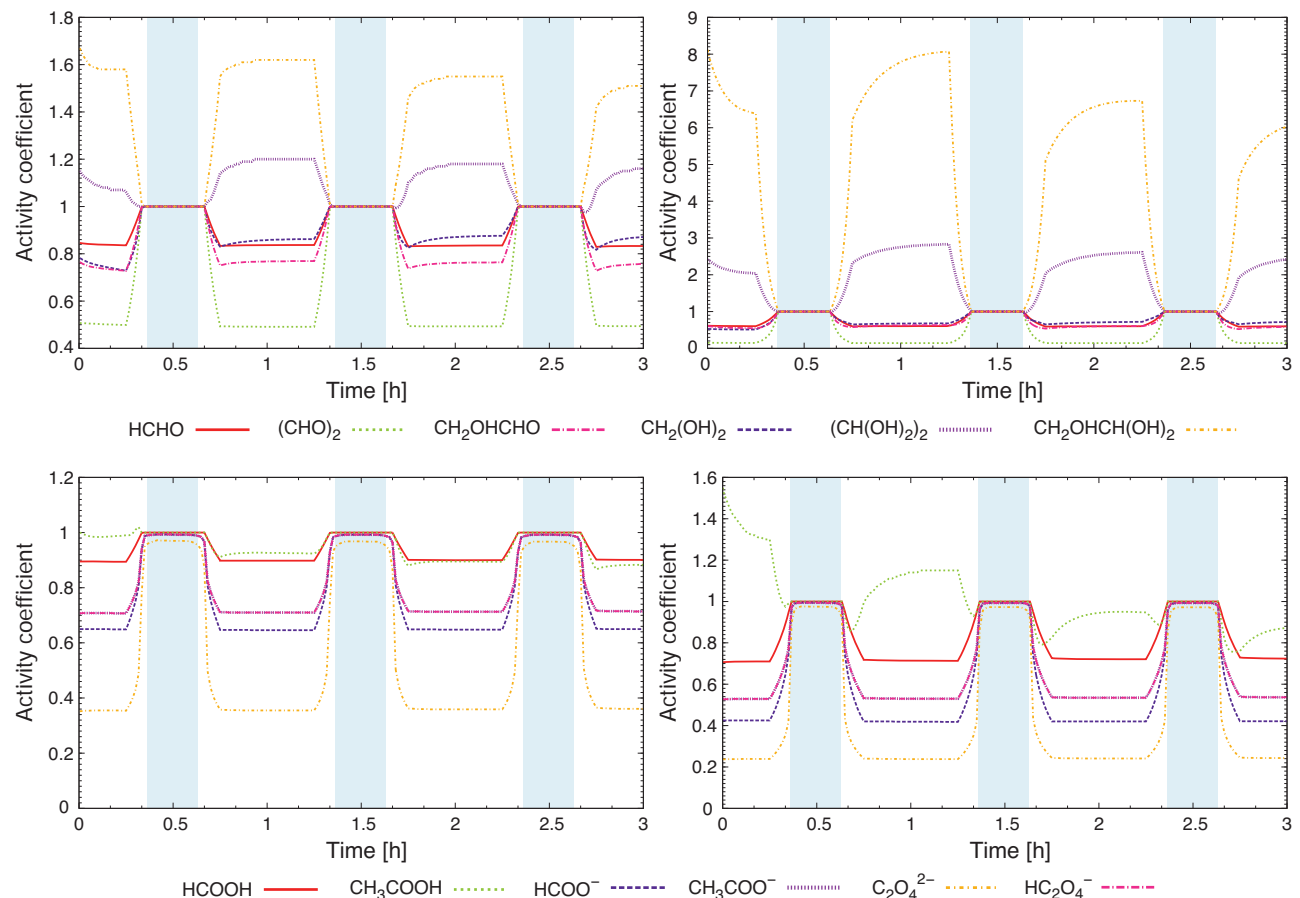

Figure 13. Modeled activity coefficients of organic carbonyl compounds (top) and organic acids/anions (TMIs, down) as the function of the simulation time for the two different relative humidity cases (left: $90 \% \mathrm{RH}$, right: $70 \% \mathrm{RH}$ ). The blue bars mark the in-cloud time periods during the simulation time.

charge state $3+$ deviate a bit more from the one than less charged ions. Under concentrated deliquesced particle conditions, the activity coefficients of ions are much lower and show a strong dependence on the relative humidity level. In the $90 \%$ RH case, the activity coefficients of singly charged ions are in the range of $0.6-0.7$, whereas the modeled coefficients for the doubly and triply charged ions are $0.3-0.35$ and 0.1 , respectively. Additionally, Fig. 12 reveals that the deviations from ideal behavior strongly depend on the species regarded but mainly on the charge state. The comparison with the $70 \% \mathrm{RH}$ case shows clearly that the activity coefficients do not change linearly with relative humidity. This fact is caused by a nonlinear change in activity coefficients in terms of the molality due to the different types of interactions in the solution. From Fig. 10 it can be seen that the activity coefficients of singly or doubly charged ions are significantly lowered in the $70 \% \mathrm{RH}$ case compared to the $90 \% \mathrm{RH}$ case. However, no substantial decrease is simulated for triply charged ions such as $\mathrm{Fe}^{3+}$, which are still in the range of 0.1 . Interestingly, the activity coefficients of $\mathrm{H}^{+}$show only a drop of 0.1 between the two cases, while the activity coefficients of other singly charged ions are lowered by approximately 0.2 .

In total, the simulated activity coefficients of inorganic ions with values below 1 imply that the mass fluxes of chemical processes in deliquesced particles involving those ions are most likely decreased, leading thus to a different chemi- cal regime than present under ideal cloud conditions. For example, the huge differences in the activity coefficients of the TMIs can lead to substantial differences in the redox cycling.

\section{Modeled activity coefficients of important organic compounds}

Figure 13 illustrates the modeled time evolution of the activity coefficients of important organic carbonyl compounds and organic acids (both free acid and anions) for the two different relative humidity cases. For organic carbonyl compounds, the depiction reveals quite uneven pattern. For hydrated glyoxal and glycolaldehyde, the predicted activity coefficient are larger than 1 in both model cases. In contrast, activity coefficients below 1 are predicted for the other unhydrated organic carbonyls and the hydrated formaldehyde. As shown for the organic ions, there is a strong dependence of the non-ideal behavior on the species and their specific forms (i.e., functional groups included) as well as additionally the relative humidity conditions. For the hydrated glyoxal and glycolaldehyde with more than $3 \mathrm{OH}$ functionalities included, activity coefficient values of about 1.2 and 1.6, respectively, are modeled in the $90 \% \mathrm{RH}$ case. Many times higher activity coefficients are calculated for the $70 \% \mathrm{RH}$ case.

The predicted activity coefficients of the organic acid anions behave similarly to the inorganic ions. Differences can be observed for the two free acids plotted in Fig. 13. While 

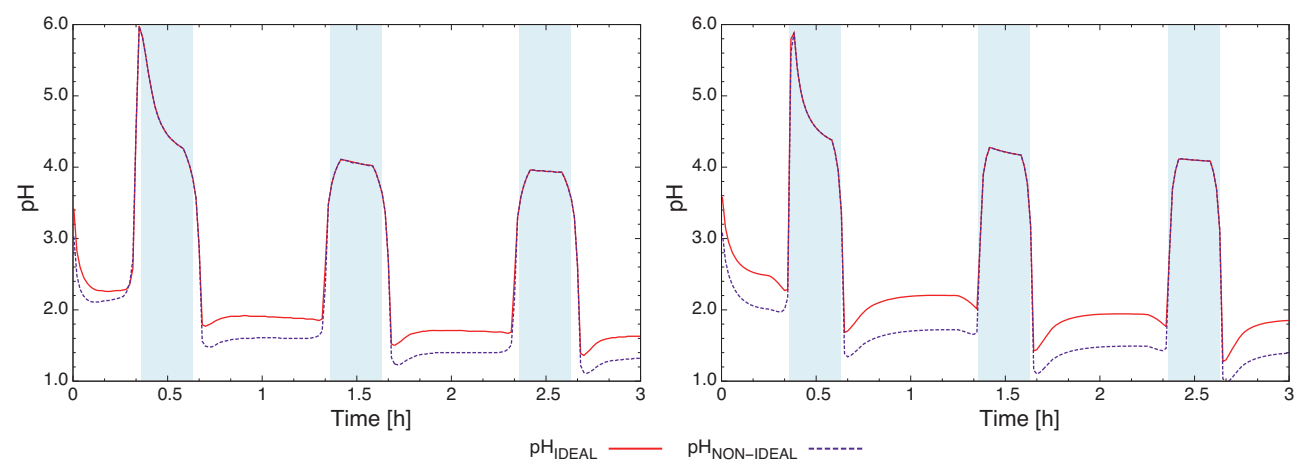

Figure 14. Modeled $\mathrm{pH}$ values as the function of the simulation time for the two different relative humidity cases (left: $90 \% \mathrm{RH}$; right: $70 \% \mathrm{RH}$ ) considering ideal (red line) and non-ideal (blue line) solutions, respectively. The blue bars mark the in-cloud time periods during the simulation time.

the activity coefficient of formic and acetic acid corresponds mainly to the present supersaturation of 0.9 in the $90 \% \mathrm{RH}$ case, the activity coefficient of acetic acid are higher during the more concentrated case at $70 \% \mathrm{RH}$. This behavior is caused by the additional methyl group. In summary, the predicted activity coefficients of organic compounds imply that the chemical processing of organics can be either increased or decreased under deliquesced particle conditions depending on the particular compound.

\section{Modeled acidity}

The modeled $\mathrm{pH}$-values for the four different simulations are plotted in Fig. 14. The pH values simulated with and without consideration of non-ideal solution effects reveal no difference during the cloud periods but substantial deviations during the non-cloud periods. During the cloud periods under almost ideal conditions, an decrease in the $\mathrm{pH}$ value is modeled due to occurring acidifying reactions such as the $\mathrm{S}(\mathrm{IV})$ to $\mathrm{S}(\mathrm{VI})$ conversion. The acidification is strongest during the first cloud passage and lower during the two following clouds. From the two plots, it can be seen that the difference between the ideal and non-ideal case is somewhat larger for the $70 \%$ case. On average, the $\mathrm{pH}$ values of the simulations considering solution non-ideality are -0.27 and $-0.44 \mathrm{pH}$ units lower under 90 and $70 \%$ RH conditions, respectively. This lower acidity in the non-ideal case is able to affect both aqueous-phase chemical reactions (i.e., acid catalyzed reactions) and all dissociations. Further implications of this difference for the chemical processing are not discussed here, but outlined in a companion paper (Rusumdar et al., 2016).

Overall, the performed simulations demonstrated that the further developed SPACCIM performs well, and the simulation results emphasize the consideration of solution nonideality in multiphase chemistry models, especially for an adequate description of the chemical aerosol processing in deliquesced particles.

\section{Summary}

In the present work, a robust and comprehensive model framework is developed and implemented in order to treat the aqueous-phase chemistry considering non-ideal solution effects in the context of the SPACCIM multiphase model. The implemented group-contribution concept enables the reliable estimation of activity coefficients for organic-inorganic mixtures composed of various ions and functional groups. Treatment of solution non-ideality for mixed-solvent systems requires a careful combination of standard-state properties with activity coefficient models. This was achieved in practice by ensuring the correct representation of Gibbs excess energy by three contributions to the excess Gibbs energy. Surface tension depreciation due to the organic compounds is effectively accounted and included in the model framework. Interaction parameters account for various contributions of interactions. Mixed organic-inorganic systems from the literature are critically assessed and a new database is created. For all tested types of systems and data, the SpactMod designed model has been shown to reproduce both the original model results and experimental results with good accuracy. Sensitivity studies have shown that the inclusion of middlerange interaction contributions is necessary. This inclusion enhances the robustness of the model. The current developed framework is open to extension to further organic functional groups, and ions, when thermodynamic data on such systems become available. Indeed, compound specific parameter, such as charge, organic functional groups and interaction parameters, required for the activity coefficient model as well as chemical reaction data are read from input files. The interaction parameters will be easily incorporated and the database can be flexibly updated. Besides, the computer code will facilitate the changes and future inclusions. The implemented numerical schemes merely give good computational efficiency. Due to the limitations regarding the lack of experimental data, and the ability to treat the organic-electrolyte mixtures of atmospheric relevance at various complexities, 
predictions are improved considerably while using extended interaction parameters. In future, the database will be extended with new parameters of recent studies (Zuend et al., 2011; Mohs and Gmehling, 2013; Ganbavale et al., 2015) within this activity coefficient module. First test simulations with the advanced SPACCIM have demonstrated the applicability of SpactMod within the model framework. Furthermore, the simulations emphasize that the treatment of solution non-ideality is mandatory for modeling multiphase chemistry processes in deliquesced particles. For important ions, the model runs have shown activity coefficients $<1$ and a strong dependency on the charge state as well as on the mi- crophysical conditions. Thus, the model results imply that the chemical processing of ions in deliquesced particles is potentially lowered and different to a chemical regime present under ideal cloud conditions. For organic compounds, the modeled activity coefficients the activity coefficients are both lower and higher than unity suggesting that the chemical processing of organics can be either increased or decreased under deliquesced particle conditions depending on the particular species. The complexity of consideration of non-ideal solutions and its influence on multiphase chemistry is investigated in detail in a companion paper (Rusumdar et al., 2016). 


\section{Appendix A: SPACCIM's activity coefficient module}

\section{Middle-range contribution-model extension}

The activity coefficients responsible for the MR interaction forces are obtained by differentiating Eq. (30) with respect to the number of moles of solvent main groups, cations, and anions, respectively. Thus, expressions for a specific cation $c^{*}$ on a mole fraction basis can be written as

$$
\begin{aligned}
& \ln \gamma_{c^{*}}^{\mathrm{MR},(x), \infty}= \\
& \quad \frac{1}{M_{\mathrm{av}}} \sum_{k} B_{k, c^{*}}(I) x_{k}^{\prime}+\frac{z_{c^{*}}^{2}}{2 M_{\mathrm{av}}} \sum_{k} \sum_{i} B_{k, i}^{\prime}(I) x_{k}^{\prime} m_{i} \\
& \quad+\sum_{a} B_{c^{*}, a}(I) m_{a}+\frac{z_{c^{*}}^{2}}{2} \sum_{c} \sum_{a} B_{c, a}^{\prime}(I) m_{c} m_{a} \\
& \quad+\sum_{a} C_{c^{*}, a}(I) m_{a} \sum_{i} m_{i}\left|z_{i}\right| \\
& \quad+\sum_{c} \sum_{a}\left[C_{c, a}(I)\left|z_{c^{*}}\right|+C_{c, a}^{\prime}(I) \frac{z_{c^{*}}^{2}}{2} \sum_{i} m_{i}\left|z_{i}\right|\right] m_{c} m_{a} \\
& \quad+\sum_{c} R_{c^{*}, c} m_{c}+\sum_{c} \sum_{a} Q_{c, c^{*}, a} m_{c} m_{a} .
\end{aligned}
$$

For a better understanding, Eq. (A1) can be divided into different terms:

$$
\begin{aligned}
\ln \gamma_{i}^{\mathrm{MR}} & =T_{i}^{\text {solvent }}+T_{i}^{\text {ion-solvent }}+T_{i}^{\text {ion }} \\
& +T_{i}^{\text {ion-ion }}+T_{i}^{\text {ternary }}
\end{aligned}
$$

with

$$
\begin{aligned}
& T_{i}^{\text {solvent }}=\frac{1}{M_{\mathrm{av}}} \sum_{k} B_{k, c^{*}}(I) x_{k}^{\prime}, \\
& T_{i}^{\text {solvent }}=\frac{1}{M_{\mathrm{av}}} \sum_{k} B_{k, c^{*}}(I) x_{k}^{\prime}, \\
& T_{i}^{\text {ion }}=\sum_{a} B_{c^{*}, a}(I) m_{a}+\sum_{c} R_{c^{*}, c} m_{c} \\
& \quad+\sum_{a} C_{c^{*}, a}(I) m_{a} \sum_{i} m_{i}\left|z_{i}\right|, \\
& \quad+\sum_{c}^{\text {ion-ion }}=\frac{z_{c^{*}}^{2}}{2} \sum_{c} \sum_{a} B_{c, a}^{\prime}(I) m_{c} m_{a}(I)\left|z_{c^{*}}\right| \\
& \left.\quad+C_{c, a}^{\prime}(I) \frac{z_{c^{*}}^{2}}{2} \sum_{i} m_{i}\left|z_{i}\right|\right] m_{c} m_{a}, \\
& T_{i}^{\text {ternary }}=\sum_{c} \sum_{a} Q_{c, c^{*}, a} m_{c} m_{a} .
\end{aligned}
$$

The term $T^{\text {ternary }}$ stands for the ternary terms in Eq. (30), which was incorporated by Zuend et al. (2008) to improve the treatment of systems at high ionic strength.

As mentioned in Sect. 3, the SpactMod activity coefficient module is substantially based on AIOMFAC (Zuend et al.,
2008). But it has been extended by including the new interaction parameters for the species shown in Fig. 4, based on mod. LIFAC (Kiepe et al., 2006). A sufficient evaluation was performed using the actual experimental database, which has been significantly enlarged within the last years (see Raatikainen and Laaksonen, 2005; Tong et al., 2008).

The general concentration dependence of the interaction parameters can be written as analogous to Eq. (31):

$B_{i, j}=b_{i, j}+c_{i, j} \exp \left(a_{1} \sqrt{I}\right)$

where $b_{i, j}, c_{i, j}$ and $a_{1}$ are adjustable interaction parameters. However, according to mod. LIFAC (Kiepe et al., 2006), the second virial coefficient $B_{i, j}$ is the interaction coefficient between the species $i$ and $j$. The relations of the ion $\leftrightarrow$ ion interaction parameter $B_{c, a}$ and ion $\leftrightarrow$ solvent group interaction parameter $B_{k}$,ion to the ionic strength are described by Kiepe et al. (2006).

$$
\begin{aligned}
& B_{c, a}=b_{c, a}+c_{c, a} \exp (-\sqrt{I}+0.125 I), \\
& B_{k, i}=b_{k, i}+c_{k, i} \exp (-1.2 \sqrt{I}+0.25 I) .
\end{aligned}
$$

The equation for interaction parameters shown in the two versions (Eqs. 31-32, A9 and A10) was compared and the final model equations are derived. As a result, Eq. (A9) can be written as similar to Eq. (32):

$$
B_{c, a}(I)=b_{c, a}+c_{c, a} \exp (-(1.0-0.125 \sqrt{I}) \sqrt{I})
$$

Based on this, while using the similar model equations, the database was utilized with the ion $\leftrightarrow$ ion interaction parameters as

$b_{c, a}^{(1)}=b_{c, a}, b_{c, a}^{(2)}=c_{c, a}, b_{c, a}^{(3)}=(1.0-0.125 \sqrt{I})$.

Since ion $\leftrightarrow$ ion $\leftrightarrow$ ion interaction parameters (ternary interactions) were not available with mod. LIFAC, the interaction parameters for $c_{c, a}^{(1)}$ and $c_{c, a}^{(2)}$ were assigned to zero. Similar to ion $\leftrightarrow$ ion interaction parameters, the model equations to compute the solvent $\leftrightarrow$ ion interaction parameters were also modified. Compared to Eqs. (31) and (A10), the parameters are assigned as

$b_{k, i}^{(1)}=b_{k, i}, b_{k, i}^{(2)}=c_{k, i}, b_{k, i}^{(3)}=(1.2-0.125 \sqrt{I})$.

Afterwards without altering the model equations given in AIOMFAC, computation of activity coefficients for all species is performed. Even the ternary and quaternary interactions were also assigned to zero during the computation of activity coefficients for solvent groups. Hence, the model equations reduced to original model equations as described in Kiepe et al. (2006) and Yan et al. (1999). Similarly, for the ions, the ternary interactions (Eq. A6) are not considered to compute the activity coefficients, which are not explicitly described in the original AIOMFAC. So this term 
is equal to zero, and hence Eqs. (3.19) and (3.20) given in Zuend et al. (2008) lead to the original model equations (see Eq. 12 in Kiepe et al., 2006). The chemical species included in the multiphase mechanism are categorized by different classes in the input files. While using these input files, this algorithm performs a search, and gathers the information on whether the computation of interaction parameters needs to be performed according to AIOMFAC or the modified equations specified according to Kiepe et al. (2006). Thus, the adjustable interaction parameters are used to compute and are finally utilized by the activity coefficients responsible for MR interactions. 
Table A1. MR parameters $b_{k, i}^{(1)}$ and $b_{k, i}^{(2)}$ between solvents and ions (AIOMFAC - regular/mod. LIFAC - bold italic).

\begin{tabular}{|c|c|c|c|c|c|c|c|}
\hline Ion & Group & $\begin{array}{r}b_{k, i}^{(1)} \\
\left(\mathrm{kg} \mathrm{mol}^{-1}\right)\end{array}$ & $\begin{array}{r}b_{k, i}^{(2)} \\
\left(\mathrm{kg} \mathrm{mol}^{-1}\right)\end{array}$ & Ion & Group & $\begin{array}{r}b_{k, i}^{(1)} \\
\left(\mathrm{kg} \mathrm{mol}^{-1}\right)\end{array}$ & $\begin{array}{r}b_{k, i}^{(2)} \\
\left(\mathrm{kg} \mathrm{mol}^{-1}\right)\end{array}$ \\
\hline $\mathrm{Na}^{+}$ & $\mathrm{CH}_{n}$ & 0.124972 & -0.031880 & $\mathrm{Na}^{+}$ & $\mathrm{OH}$ & 0.080254 & 0.002201 \\
\hline $\mathrm{K}^{+}$ & $\mathrm{CH}_{n}$ & 0.121449 & 0.015499 & $\mathrm{~K}^{+}$ & $\mathrm{OH}$ & 0.065219 & -0.170779 \\
\hline $\mathrm{NH}_{4}^{+}$ & $\mathrm{CH}_{n}$ & 0.103096 & -0.001083 & $\mathrm{NH}_{4}^{+}$ & $\mathrm{OH}$ & 0.039373 & 0.001083 \\
\hline $\mathrm{Ca}^{2+}$ & $\mathrm{CH}_{n}$ & 0.000019 & -0.060807 & $\mathrm{Ca}^{2+}$ & $\mathrm{OH}$ & 0.839628 & -0.765776 \\
\hline $\mathrm{Mg}^{2+}$ & $\mathrm{CH}_{n}$ & -0.34610 & -0.44995 & $\mathrm{Mg}^{2+}$ & $\mathrm{OH}$ & 0.281980 & 0.07617 \\
\hline $\mathrm{Zn}^{2+}$ & $\mathrm{CH}_{n}$ & -0.10163 & -0.06578 & $\mathrm{Zn}^{2+}$ & $\mathrm{OH}$ & 0.036480 & 0.02249 \\
\hline $\mathrm{Cl}^{-}$ & $\mathrm{CH}_{n}$ & 0.014974 & 0.142574 & $\mathrm{Cl}^{-}$ & $\mathrm{OH}$ & -0.042460 & -0.128063 \\
\hline $\mathrm{NO}_{3}^{-}$ & $\mathrm{CH}_{n}$ & 0.018368 & 0.669086 & $\mathrm{NO}_{3}^{-}$ & $\mathrm{OH}$ & -0.128216 & -0.962408 \\
\hline $\mathrm{SO}_{4}^{2-}$ & $\mathrm{CH}_{n}$ & 0.101044 & -0.070253 & $\mathrm{SO}_{4}^{2-}$ & $\mathrm{OH}$ & -0.164709 & 0.574638 \\
\hline $\mathrm{Br}^{-}$ & $\mathrm{CH}_{n}$ & 0.000042 & -0.025473 & $\mathrm{Br}^{-}$ & $\mathrm{OH}$ & -0.007153 & 0.483038 \\
\hline \multirow[t]{3}{*}{$\mathrm{I}^{-}$} & $\mathrm{CH}_{n}$ & 0.01206 & -0.02777 & $\mathrm{I}^{-}$ & $\mathrm{OH}$ & -0.04479 & 0.04151 \\
\hline & & & & $\mathrm{F}^{-}$ & $\mathrm{OH}$ & 0.15233 & -0.04145 \\
\hline & & & & $\mathrm{CH}_{3} \mathrm{COO}^{-}$ & $\mathrm{OH}$ & 0.02672 & -0.02117 \\
\hline $\mathrm{Na}^{+}$ & $\mathrm{H}_{2} \mathrm{O}$ & 0.00331 & -0.00143 & $\mathrm{Na}^{+}$ & $\mathrm{CH}_{3} \mathrm{OH}$ & 0.16617 & 0.03928 \\
\hline $\mathrm{K}^{+}$ & $\mathrm{H}_{2} \mathrm{O}$ & 0.00258 & -0.00088 & $\mathrm{~K}^{+}$ & $\mathrm{CH}_{3} \mathrm{OH}$ & 0.10797 & 0.19164 \\
\hline $\mathrm{NH}_{4}^{+}$ & $\mathrm{H}_{2} \mathrm{O}$ & 0.00088 & 0.00288 & $\mathrm{NH}_{4}^{+}$ & $\mathrm{CH}_{3} \mathrm{OH}$ & 0.20529 & -0.10550 \\
\hline $\mathrm{Ca}^{2+}$ & $\mathrm{H}_{2} \mathrm{O}$ & 0.01105 & 0.00641 & $\mathrm{Ca}^{2+}$ & $\mathrm{CH}_{3} \mathrm{OH}$ & 0.37818 & 0.00247 \\
\hline $\mathrm{Mg}^{2+}$ & $\mathrm{H}_{2} \mathrm{O}$ & 0.00050 & 0.01163 & $\mathrm{Cu}^{2+}$ & $\mathrm{CH}_{3} \mathrm{OH}$ & 0.00789 & -0.06944 \\
\hline $\mathrm{Cu}^{2+}$ & $\mathrm{H}_{2} \mathrm{O}$ & -0.00571 & -0.00760 & $\mathrm{Zn}^{2+}$ & $\mathrm{CH}_{3} \mathrm{OH}$ & 0.16775 & -0.44229 \\
\hline $\mathrm{Zn}^{2+}$ & $\mathrm{H}_{2} \mathrm{O}$ & -0.01848 & 0.00001 & & & & \\
\hline $\mathrm{Cl}^{-}$ & $\mathrm{H}_{2} \mathrm{O}$ & -0.00128 & -0.00020 & $\mathrm{Cl}^{-}$ & $\mathrm{CH}_{3} \mathrm{OH}$ & -0.03352 & 0.00242 \\
\hline $\mathrm{NO}_{3}^{-}$ & $\mathrm{H}_{2} \mathrm{O}$ & 0.03228 & -0.00083 & $\mathrm{NO}_{3}^{-}$ & $\mathrm{CH}_{3} \mathrm{OH}$ & -0.07716 & -0.00669 \\
\hline $\mathrm{SO}_{4}^{2-}$ & $\mathrm{H}_{2} \mathrm{O}$ & 0.02278 & 0.00271 & $\mathrm{Br}^{-}$ & $\mathrm{CH}_{3} \mathrm{OH}$ & -0.00944 & -0.06080 \\
\hline $\mathrm{Br}^{-}$ & $\mathrm{H}_{2} \mathrm{O}$ & -0.00247 & -0.00008 & $\mathrm{I}^{-}$ & $\mathrm{CH}_{3} \mathrm{OH}$ & -0.02090 & -0.14894 \\
\hline $\mathrm{NO}_{2}^{-}$ & $\mathrm{H}_{2} \mathrm{O}$ & 0.00549 & -0.00565 & $\mathrm{~F}^{-}$ & $\mathrm{CH}_{3} \mathrm{OH}$ & 0.07436 & -0.04388 \\
\hline $\mathrm{I}^{-}$ & $\mathrm{H}_{2} \mathrm{O}$ & -0.00537 & 0.00018 & $\mathrm{CH}_{3} \mathrm{COO}^{-}$ & $\mathrm{CH}_{3} \mathrm{OH}$ & 0.00046 & 0.01249 \\
\hline $\mathrm{F}^{-}$ & $\mathrm{H}_{2} \mathrm{O}$ & 0.00652 & 0.00132 & & & & \\
\hline $\mathrm{CH}_{3} \mathrm{COO}^{-}$ & $\mathrm{H}_{2} \mathrm{O}$ & 0.01918 & 0.00230 & & & & \\
\hline $\mathrm{Na}^{+}$ & $\mathrm{CH}_{2} \mathrm{CO}$ & -0.21019 & 0.94813 & & & & \\
\hline $\mathrm{K}^{+}$ & $\mathrm{CH}_{2} \mathrm{CO}$ & -0.44195 & 1.10287 & & & & \\
\hline $\mathrm{Cl}^{-}$ & $\mathrm{CH}_{2} \mathrm{CO}$ & 0.54064 & -0.62981 & & & & \\
\hline $\mathrm{Br}^{-}$ & $\mathrm{CH}_{2} \mathrm{CO}$ & 0.48898 & -0.96778 & & & & \\
\hline $\mathrm{I}^{-}$ & $\mathrm{CH}_{2} \mathrm{CO}$ & 0.08245 & 0.03292 & & & & \\
\hline $\mathrm{CH}_{3} \mathrm{COO}^{-}$ & $\mathrm{CH}_{2} \mathrm{CO}$ & 0.26560 & -0.93032 & & & & \\
\hline
\end{tabular}


Table A2. Mod. LIFAC binary cation-anion MR interaction parameters.

\begin{tabular}{llrr}
\hline Cation & Anion & $b_{c, a}^{(1)}$ & $b_{c, a}^{(2)}$ \\
\hline $\mathrm{Na}^{+}$ & $\mathrm{F}^{-}$ & -0.00694 & -0.08166 \\
$\mathrm{Na}^{+}$ & $\mathrm{I}^{-}$ & 0.27922 & -0.13430 \\
$\mathrm{Na}^{+}$ & $\mathrm{NO}_{3}^{-}$ & 0.04425 & -0.41980 \\
$\mathrm{Na}^{+}$ & $\mathrm{CH}_{3} \mathrm{COO}^{-}$ & 0.25018 & 0.31363 \\
\hline $\mathrm{K}^{+}$ & $\mathrm{F}^{-}$ & 0.18434 & -0.28912 \\
$\mathrm{~K}^{+}$ & $\mathrm{I}^{-}$ & 0.12860 & 0.02379 \\
$\mathrm{~K}^{+}$ & $\mathrm{NO}_{3}^{-}$ & -0.06095 & -0.67019 \\
$\mathrm{~K}^{+}$ & $\mathrm{CH}_{3} \mathrm{COO}$ & 0.27327 & 0.45129 \\
\hline $\mathrm{Mg}^{+}$ & $\mathrm{Cl}^{-}$ & 0.45150 & 1.19298 \\
$\mathrm{Mg}^{+}$ & $\mathrm{Br}^{-}$ & 0.59615 & 1.37619 \\
$\mathrm{Mg}^{+}$ & $\mathrm{I}^{-}$ & 0.76336 & 1.58654 \\
$\mathrm{Mg}^{+}$ & $\mathrm{NO}_{3}^{-}$ & 0.28427 & 1.72405 \\
$\mathrm{Mg}^{+}$ & $\mathrm{SO}_{4}^{2-}$ & 0.53597 & 1.03876 \\
\hline $\mathrm{Ca}^{+}$ & $\mathrm{Br}^{-}$ & 0.60948 & 0.30140 \\
$\mathrm{Ca}^{+}$ & $\mathrm{I}^{-}$ & 0.59261 & 1.46632 \\
$\mathrm{Ca}^{+}$ & $\mathrm{SO}_{4}^{2-}$ & -15.8421 & -0.00212 \\
\hline $\mathrm{Cu}^{2+}$ & $\mathrm{Cl}^{-}$ & 0.21233 & 0.11695 \\
$\mathrm{Cu}^{2+}$ & $\mathrm{NO}_{3}^{-}$ & 0.45706 & -0.41585 \\
$\mathrm{Cu}^{2+}$ & $\mathrm{SO}_{4}^{2-}$ & 1.24148 & -5.86466 \\
\hline $\mathrm{Zn}^{2+}$ & $\mathrm{Cl}^{-}$ & 0.04463 & 0.43088 \\
\hline & & & \\
\hline
\end{tabular}


Table A3. AIOMFAC binary cation $\leftrightarrow$ anion MR interaction parameters.

\begin{tabular}{|c|c|c|c|c|c|c|}
\hline Cation & Anion & $\begin{array}{r}b_{c, a}^{(1)} \\
\left(\mathrm{kg} \mathrm{mol}^{-1}\right)\end{array}$ & $\begin{array}{r}b_{c, a}^{(2)} \\
\left(\mathrm{kg} \mathrm{mol}^{-1}\right)\end{array}$ & $\begin{array}{r}b_{c, a}^{(3)} \\
\left(\mathrm{kg}^{1 / 2} \mathrm{~mol}^{-1 / 2}\right)\end{array}$ & $\begin{array}{r}c_{c, a}^{(1)} \\
\left(\mathrm{kg}^{2} \mathrm{~mol}^{-2}\right)\end{array}$ & $\begin{array}{r}c_{c, a}^{(2)} \\
\left(\mathrm{kg}^{1 / 2} \mathrm{~mol}^{-1 / 2}\right)\end{array}$ \\
\hline $\mathrm{H}^{+}$ & $\mathrm{Cl}^{-}$ & 0.182003 & 0.243340 & 0.8 & 0.033319 & 0.504672 \\
\hline $\mathrm{H}^{+}$ & $\mathrm{Br}^{-}$ & 0.120325 & 0.444859 & 0.8 & 0.080767 & 0.596776 \\
\hline $\mathrm{H}^{+}$ & $\mathrm{NO}_{3}^{-}$ & 0.210638 & 0.122694 & 0.8 & -0.101736 & 1.676420 \\
\hline $\mathrm{H}^{+}$ & $\mathrm{SO}_{4}^{2-}$ & 0.097108 & -0.004307 & 1.0 & 0.140598 & 0.632246 \\
\hline $\mathrm{H}^{+}$ & $\mathrm{HSO}_{4}^{-}$ & 0.313812 & -4.895466 & 1.0 & -0.358419 & 0.807667 \\
\hline $\mathrm{Li}^{+}$ & $\mathrm{Cl}^{-}$ & 0.106555 & 0.206370 & 0.8 & 0.053239 & 0.535548 \\
\hline $\mathrm{Li}^{+}$ & $\mathrm{Br}^{-}$ & 0.106384 & 0.316480 & 0.8 & 0.057602 & 0.464658 \\
\hline $\mathrm{Li}^{+}$ & $\mathrm{NO}_{3}^{-}$ & 0.076313 & 0.300550 & 0.8 & 0.046701 & 0.664928 \\
\hline $\mathrm{Li}^{+}$ & $\mathrm{SO}_{4}^{2-}$ & 0.114470 & 0.035401 & 0.8 & -0.263258 & 1.316967 \\
\hline $\mathrm{Na}^{+}$ & $\mathrm{Cl}^{-}$ & 0.053741 & 0.079771 & 0.8 & 0.024553 & 0.562981 \\
\hline $\mathrm{Na}^{+}$ & $\mathrm{Br}^{-}$ & 0.180807 & 0.273114 & 0.8 & -0.506578 & 2.209050 \\
\hline $\mathrm{Na}^{+}$ & $\mathrm{NO}_{3}^{-}$ & 0.001164 & -0.102546 & 0.410453 & 0.002535 & 0.512657 \\
\hline $\mathrm{Na}^{+}$ & $\mathrm{SO}_{4}^{2-}$ & 0.001891 & -0.424184 & 0.8 & -0.223851 & 1.053620 \\
\hline $\mathrm{Na}^{+}$ & $\mathrm{HSO}_{4}^{-}$ & 0.021990 & 0.001863 & 0.8 & 0.019921 & 0.619816 \\
\hline $\mathrm{K}^{+}$ & $\mathrm{Cl}^{-}$ & 0.016561 & -0.002752 & 0.8 & 0.020833 & 0.670530 \\
\hline $\mathrm{K}^{+}$ & $\mathrm{Br}^{-}$ & 0.033688 & 0.060882 & 0.8 & 0.015293 & 0.565063 \\
\hline $\mathrm{K}^{+}$ & $\mathrm{NO}_{3}^{-}$ & 0.000025 & -0.413172 & 0.357227 & -0.000455 & 0.342244 \\
\hline $\mathrm{K}^{+}$ & $\mathrm{SO}_{4}^{2-}$ & 0.004079 & -0.869936 & 0.8 & -0.092240 & 0.918743 \\
\hline $\mathrm{NH}_{4}^{+}$ & $\mathrm{Cl}^{-}$ & 0.001520 & 0.049074 & 0.116801 & 0.011112 & 0.653256 \\
\hline $\mathrm{NH}_{4}^{+}$ & $\mathrm{Br}^{-}$ & 0.002498 & 0.081512 & 0.143621 & 0.013795 & 0.728984 \\
\hline $\mathrm{NH}_{4}^{+}$ & $\mathrm{NO}_{3}^{-}$ & -0.000057 & -0.171746 & 0.260000 & 0.005510 & 0.529762 \\
\hline $\mathrm{NH}_{4}^{+}$ & $\mathrm{SO}_{4}^{2-}$ & 0.000373 & -0.906075 & 0.545109 & -0.000379 & 0.354206 \\
\hline $\mathrm{NH}_{4}^{+}$ & $\mathrm{HSO}_{4}^{-}$ & 0.009054 & 0.214405 & 0.228956 & 0.017298 & 0.820465 \\
\hline $\mathrm{Mg}^{2+}$ & $\mathrm{Cl}^{-}$ & 0.195909 & 0.332387 & 0.8 & 0.072063 & 0.397920 \\
\hline $\mathrm{Mg}^{2+}$ & $\mathrm{NO}_{3}^{-}$ & 0.430671 & 0.767242 & 0.8 & -0.511836 & 1.440940 \\
\hline $\mathrm{Mg}^{2+}$ & $\mathrm{SO}_{4}^{2-}$ & 0.122364 & -3.425876 & 0.8 & -0.738561 & 0.864380 \\
\hline $\mathrm{Ca}^{2+}$ & $\mathrm{Cl}^{-}$ & 0.104920 & 0.866923 & 0.8 & 0.072063 & 0.365747 \\
\hline $\mathrm{Ca}^{2+}$ & $\mathrm{NO}_{3}^{-}$ & 0.163282 & 0.203681 & 0.8 & -0.075452 & 1.210906 \\
\hline
\end{tabular}


Table A4. UNIFAC interaction parameter (E-AIM). Values from Peng et al. (2001) are presented in bold italic.

\begin{tabular}{|c|c|c|c|c|c|c|c|c|c|c|}
\hline Organics & $\mathrm{CH}_{n}$ & $\mathrm{OH}$ & $\mathrm{CH}_{3} \mathrm{OH}$ & $\mathrm{H}_{2} \mathrm{O}$ & $\mathrm{CH}_{2} \mathrm{CO}$ & $\mathrm{CHO}$ & $\mathrm{CCOO}$ & HCOO & $\mathrm{CH}_{2} \mathrm{O}$ & $\mathrm{COOH}$ \\
\hline $\mathrm{CH}_{n}$ & 0.0 & 986.5 & 697.2 & 1318.0 & 476.4 & 677.0 & 232.1 & 507.00 & 251.5 & 663.5 \\
\hline $\mathrm{OH}$ & 156.4 & 0.0 & -137.1 & 276.4 & 84 & -203.60 & 101.1 & 267.80 & 28.06 & 224.39 \\
\hline $\mathrm{CH}_{3} \mathrm{OH}$ & 16.51 & 249.1 & 0.0 & -181.0 & 23.39 & 306.4 & -10.72 & 179.70 & -128.60 & -202 \\
\hline $\mathrm{H}_{2} \mathrm{O}$ & -89.71 & -153.0 & 289.6 & 0.0 & -195.4 & -116.0 & 72.870 & 233.87 & 540.5 & -69.29 \\
\hline $\mathrm{CH}_{2} \mathrm{CO}$ & 26.76 & 164.5 & 108.7 & 472.5 & 0.0 & -37.36 & -213.7 & -190.40 & -103.60 & 669.4 \\
\hline $\mathrm{CHO}$ & 505.7 & 529.00 & -340.2 & 480.80 & 128.0 & 0.0 & -110.3 & 766.00 & 304.1 & 497.5 \\
\hline $\mathrm{CCOO}$ & 114.8 & 245.40 & 249.63 & 200.0 & 372.2 & 185.10 & 0.0 & -241.80 & -235.7 & 660.2 \\
\hline $\mathrm{HCOO}$ & 329.30 & 139.40 & 227.80 & 124.63 & 385.40 & -236.50 & 1167.0 & 0.0 & -234.00 & -268.1 \\
\hline $\mathrm{CH}_{2} \mathrm{O}$ & 83.36 & 237.7 & 238.40 & -314.7 & 191.10 & -7.838 & 461.3 & 457.30 & 0.0 & 664.00 \\
\hline $\mathrm{COOH}$ & 315.3 & -103.03 & 339.80 & -145.88 & -297.8 & -165.50 & -256.3 & 193.90 & -338.5 & 0.0 \\
\hline
\end{tabular}

Table A5. UNIFAC relative van der Waals group volume $\left(R_{k}\right)$ and surface area $\left(Q_{k}\right)$ parameters for solvent groups.

\begin{tabular}{|c|c|c|c|c|c|}
\hline No. & Family name & Main group & Subgroup & $R_{t}$ & $Q_{t}$ \\
\hline \multirow[t]{4}{*}{1} & \multirow{4}{*}{ Alkane } & \multirow[t]{4}{*}{$C H_{n}(n=0,1,2,3)$} & $\mathrm{CH} 3$ & 0.9011 & 0.848 \\
\hline & & & $\mathrm{CH} 2$ & 0.6744 & 0.540 \\
\hline & & & $\mathrm{CH}$ & 0.4469 & 0.228 \\
\hline & & & $\mathrm{C}$ & 0.2195 & 0.00 \\
\hline 2 & Alcohol & $\mathrm{OH}$ & $\mathrm{OH}$ & 1.0000 & 1.20 \\
\hline 3 & Water & $\mathrm{H}_{2} \mathrm{O}$ & $\mathrm{H}_{2} \mathrm{O}$ & 0.9200 & 1.400 \\
\hline 4 & Methanol & $\mathrm{CH}_{3} \mathrm{OH}$ & $\mathrm{CH}_{3} \mathrm{OH}$ & 1.4311 & 1.432 \\
\hline \multirow[t]{2}{*}{5} & \multirow[t]{2}{*}{ Carbonyl } & \multirow[t]{2}{*}{$\mathrm{CH}_{2} \mathrm{CO}$} & $\mathrm{CH}_{3} \mathrm{CO}$ & 1.6724 & 1.488 \\
\hline & & & $\mathrm{CH}_{2} \mathrm{CO}$ & 1.4457 & 1.180 \\
\hline 6 & Aldehyde & $\mathrm{CHO}$ & $\mathrm{CHO}$ & 0.9980 & 0.948 \\
\hline \multirow[t]{2}{*}{7} & \multirow[t]{2}{*}{ Acetate } & \multirow[t]{2}{*}{$\mathrm{CCOO}$} & $\mathrm{CH}_{3} \mathrm{COO}$ & 1.9031 & 1.728 \\
\hline & & & $\mathrm{CH}_{2} \mathrm{COO}$ & 1.6764 & 1.420 \\
\hline 8 & Formate & $\mathrm{HCOO}$ & $\mathrm{HCOO}$ & 1.2420 & 1.188 \\
\hline \multirow[t]{3}{*}{9} & \multirow[t]{3}{*}{ Ether } & \multirow[t]{3}{*}{$\mathrm{CH}_{2} \mathrm{O}$} & $\mathrm{CH}_{3} \mathrm{O}$ & 1.1450 & 1.088 \\
\hline & & & $\mathrm{CH}_{2} \mathrm{O}$ & 0.9183 & 0.780 \\
\hline & & & $\mathrm{CH}-\mathrm{O}$ & 0.6908 & 0.468 \\
\hline \multirow[t]{2}{*}{10} & \multirow[t]{2}{*}{ Carboxylic acid } & \multirow[t]{2}{*}{$\mathrm{COOH}$} & $\mathrm{COOH}$ & 1.3013 & 1.224 \\
\hline & & & $\mathrm{HCOOH}$ & 1.5280 & 1.532 \\
\hline
\end{tabular}


Table A6. Relative van der Waals subgroup volume $\left(R_{t}^{\mathrm{H}}\right)$ and surface area $\left(Q_{t}^{\mathrm{H}}\right)$ parameters for cations and anions considering dynamic hydration. Values from AIOMFAC and mod. LIFAC are presented in regular and bold italic, respectively.

\begin{tabular}{|c|c|c|c|c|c|c|}
\hline Ion & $\mathrm{ADHN}^{\mathrm{a}, \mathrm{b}}$ & $R_{t}$ & $Q_{t}$ & $R_{t}^{\mathrm{H}, \mathrm{c}}$ & $Q_{t}^{\mathrm{H}, \mathrm{c}}$ & Reference \\
\hline $\mathrm{H}^{+}$ & 1.93 & 0.0 & 0.0 & 1.78 & 2.70 & Zuend et al. (2008) \\
\hline $\mathrm{Na}^{+}$ & 0.22 & 0.18 & 0.18 & 0.38 & 0.62 & Zuend et al. (2008) \\
\hline $\mathrm{K}^{+}$ & 0.00 & 0.44 & 0.58 & 0.440 & 0.58 & Zuend et al. (2008) \\
\hline $\mathrm{NH}_{4}^{+}$ & 0.00 & 0.69 & 0.78 & 0.69 & 0.78 & Zuend et al. (2008) \\
\hline $\mathrm{Mg}^{2+}$ & 5.85 & 0.06 & 0.16 & 5.44 & 8.35 & Zuend et al. (2008) \\
\hline $\mathrm{Ca}^{2+}$ & 2.10 & 0.31 & 0.46 & 2.24 & 3.40 & Zuend et al. (2008) \\
\hline $\mathrm{Fe}^{2+}$ & 0.00 & 0.90 & 0.84 & 0.901 & 0.84 & $\mathrm{~d}$ \\
\hline $\mathrm{Cu}^{2+}$ & 0.00 & 0.13 & 0.26 & 0.13 & 0.26 & Kiepe et al. (2006) \\
\hline $\mathrm{Mn}^{2+}$ & 0.00 & 0.90 & 0.84 & 0.901 & 0.84 & $\mathrm{~d}$ \\
\hline$Z_{n}^{2+}$ & 2.18 & 0.12 & 0.24 & 2.12 & 3.29 & Kiepe et al. (2006) \\
\hline $\mathrm{Cl}^{-}$ & 0.00 & 0.99 & 0.99 & 0.99 & 0.99 & Zuend et al. (2008) \\
\hline $\mathrm{Br}^{-}$ & 0.00 & 1.25 & 1.16 & 1.25 & 1.16 & Zuend et al. (2008) \\
\hline $\mathrm{NO}_{3}^{-}$ & 0.00 & 0.95 & 0.97 & 0.95 & 0.97 & Zuend et al. (2008) \\
\hline $\mathrm{HSO}_{4}^{-}$ & 0.00 & 1.65 & 1.40 & 1.65 & 1.40 & Zuend et al. (2008) \\
\hline $\mathrm{SO}_{4}^{2-}$ & 1.83 & 1.66 & 1.40 & 3.34 & 3.96 & Zuend et al. (2008) \\
\hline $\mathrm{OH}^{-}$ & 2.80 & 1.16 & 1.27 & 3.74 & 5.196 & Kiepe et al. (2006) \\
\hline $\mathrm{CO}_{3}^{2-}$ & 0.00 & 2.06 & 2.25 & 2.06 & 2.26 & Kiepe et al. (2006) \\
\hline $\mathrm{NO}_{2}^{-}$ & 0.00 & 1.52 & 1.68 & 1.52 & 1.6 & Kiepe et al. (2006) \\
\hline$I^{-}$ & 0.00 & 1.55 & 1.34 & 1.55 & 1.34 & Kiepe et al. (2006) \\
\hline$F^{-}$ & 5.02 & 0.29 & 0.44 & 4.92 & 7.45 & Kiepe et al. (2006) \\
\hline $\mathrm{HCOO}^{-}$ & 0.00 & 0.901 & 0.84 & 0.901 & 0.84 & d \\
\hline $\mathrm{CH}_{3} \mathrm{COO}^{-}$ & 0.00 & 1.74 & 1.04 & 1.74 & 1.0437 & Kiepe et al. (2006) \\
\hline $\mathrm{HOOCCH}_{2} \mathrm{COO}^{-}$ & 0.00 & 0.901 & 0.84 & 0.901 & 0.84 & d \\
\hline $\mathrm{HOOCC}_{2} \mathrm{H}_{4} \mathrm{COO}^{-}$ & 0.00 & 0.901 & 0.84 & 0.901 & 0.84 & d \\
\hline $\mathrm{HCO}_{3}^{-}$ & 0.00 & 0.901 & 0.84 & 0.901 & 0.84 & $\mathrm{~d}$ \\
\hline $\mathrm{CHOCOO}^{-}$ & 0.00 & 0.901 & 0.84 & 0.901 & 0.84 & d \\
\hline
\end{tabular}

a The apparent dynamic hydration numbers (ADHN) at 303.15 K and 0.1 M are taken from Kiriukhin and Collins (2002).

${ }^{b}$ Values of $\mathrm{ADHN}=0$ are assigned to the ions for which the data are unavailable. ${ }^{\mathrm{c}}$ Calculated using Eqs. (34) and (35),

respectively. ${ }^{\mathrm{d}} \mathrm{ADHN}$ data are not available. 
Appendix B: List of symbols, indices and acronyms

Table B1. List and description of symbols and indices.

\begin{tabular}{|c|c|}
\hline Symbol/index & Description \\
\hline$a_{i}$ & Activity of species $i$ \\
\hline$a_{A}$ & Activity of compound $A$ \\
\hline$a_{i}^{k}$ & Activity of species $i$ in the $k$ th particle/cloud droplet class \\
\hline$a_{\mathrm{W}}$ & Water activity \\
\hline$a_{\mathrm{w}}^{k}$ & Water activity in the $k$ th particle/cloud droplet class \\
\hline$A_{(\mathrm{aq})}$ & Compound $A$ in the aqueous phase \\
\hline$A_{(\mathrm{g})}$ & Compound $A$ in the gas phase \\
\hline$A$ & Debye-Hückel parameter \\
\hline$b$ & Debye-Hückel parameter \\
\hline$B_{c, a}(I)$ & Ionic strength-dependent binary interaction coefficient between cations and anions \\
\hline$b_{k, i}^{(1)}, b_{k, i}^{(2)}, b_{c, a}^{(1)}, b_{c, a}^{(2)}, c_{c, a}^{(1)}, c_{c, a}^{(2)}$ & Fitted parameters (AIOMFAC) \\
\hline $\begin{array}{l}B_{k, i}(I) \\
c^{*}\end{array}$ & $\begin{array}{l}\text { Ionic strength-dependent binary interaction coefficient between solvent main groups and ions } \\
\text { Specific cation }\end{array}$ \\
\hline$C_{c, a}(I)$ & Interaction coefficient between cation $\leftrightarrow$ anion pairs with respect to the total charge concentration \\
\hline$c^{\mathrm{G}}$ & Vector of the concentrations of the gas-phase species \\
\hline$c_{i}$ & Mass concentration of an aqueous-phase species $i$ \\
\hline$c_{i, k}^{\mathrm{s}}$ & Saturation vapor mole concentration \\
\hline$c_{i^{*}}^{\mathrm{G}_{\mathrm{K}}^{\mathrm{n}}}$ & $i^{*}$ th gas-phase chemical species \\
\hline$c^{k}$ & Vector of all concentrations \\
\hline$c_{i}^{k}$ & $i$ th aqueous-phase chemical species in the $k$ th particle/cloud droplet class \\
\hline$c_{\mathrm{sol}}$ & Solute concentration \\
\hline$c_{\mathrm{sol}}^{k}$ & Solute concentration in the $k$ th particle class \\
\hline$D_{i}^{\mathrm{G}}$ & Gas diffusion coefficient \\
\hline$F\left(c_{l}^{1}, \ldots, c_{l}^{M}\right)$ & Mass transfer between different droplet classes by microphysical processes \\
\hline$G_{\mathrm{LR}}^{\mathrm{ex}}$ & Long-range (LR) electrostatic interactions contributing to excess Gibbs free energy \\
\hline$G_{\mathrm{MR}}^{\mathrm{ex}}$ & Middle-range (MR) electrostatic interactions contributing to excess Gibbs free energy \\
\hline$G_{S R}^{\mathrm{MX}}$ & Short-range (SR) electrostatic interactions contributing to excess Gibbs free energy \\
\hline$G^{\mathrm{sk}}\left(p, T, n_{j}\right)$ & Excess Gibbs energy \\
\hline$H_{i}$ & Dimensionless Henry's law constant of species $i$ \\
\hline$i, i^{*}$ & Species index \\
\hline I & Identity matrix \\
\hline$I$ & Ionic strength \\
\hline$j$ & Species index \\
\hline $\mathbf{J}$ & Approximation of the Jacobian \\
\hline$k=1, \ldots, M$ & Particle/cloud droplet class index \\
\hline$k_{t}^{k i}$ & Mass transfer coefficient of species $i$ into the $k$ th particle/cloud droplet class \\
\hline$\stackrel{l}{K_{\mathrm{eq}}}$ & Equilibrium constant \\
\hline$K_{i}^{\mathrm{H}}$ & Henry's law constant of species $i$ \\
\hline$L^{t}$ & Liquid water content \\
\hline$L_{k}$ & Liquid water content of the $k$ th droplet class inside the box volume \\
\hline$m_{A}$ & Molality of compound $A$ \\
\hline$M_{\mathrm{c}}$ & Molar mass of carbon \\
\hline$m_{i}$ & Molality of an aqueous-phase species $i$ \\
\hline$m_{i}^{k}$ & Molality of dissolved gas-phase species $i$ in particle class $k$ \\
\hline
\end{tabular}


Table B1. Continued.

\begin{tabular}{|c|c|}
\hline Symbol/Index & Description \\
\hline$m_{j}$ & Molality of the $j$ th species \\
\hline $\operatorname{mol}_{\text {sol }_{i}}^{k}$ & Moles of soluble material of the $i$ th species in the $k$ th particle/droplet class \\
\hline$M_{\text {sol }}$ & Mean molar mass of solute \\
\hline$M_{S}$ & Molar mass of solvent $s$ \\
\hline $\operatorname{mol}_{\mathrm{w}}^{k}$ & Molar water fraction \\
\hline$N_{\mathrm{A}}$ & Number of aqueous-phase species \\
\hline$n_{a}$ & Moles of anions \\
\hline$N_{t}^{\mathrm{ADH}}$ & Dynamic hydration numbers \\
\hline$n_{c} n_{c^{\prime}}$ & Moles of cations \\
\hline$n_{\mathrm{cb}}$ & Number of carbon atoms \\
\hline$N_{\mathrm{G}}$ & Number of gas-phase species \\
\hline$n_{j}$ & Number of moles of component $j$ \\
\hline$p$ & Total pressure \\
\hline$p_{i, k}^{\mathrm{s}}$ & Saturation vapor pressure of gas-phase species $i$ over a particle in size bin $k$ \\
\hline$p_{\mathrm{W}}$ & Equilibrium partial pressure of water over the solution droplet \\
\hline$p_{\mathrm{W}}^{\mathrm{o}}$ & Equilibrium water vapor pressure over a flat surface of pure water \\
\hline$Q_{c, c^{\prime} a}(I)$ & Ternary interaction coefficient involving two different cations \\
\hline$q_{i} / r_{i}$ & Surface area/volume of component $i$ \\
\hline$r_{A}$ & Reaction rate \\
\hline$r_{\text {drop }}(\mathrm{m})$ & Mean wet droplet radius \\
\hline$r_{k}$ & Droplet radius of the $k$ th particle/cloud droplet class \\
\hline$R$ & Universal gas constant \\
\hline$R_{c, c^{\prime}}(I)$ & Binary interaction coefficient involving two different cations \\
\hline $\mathrm{RH}$ & Ambient relative humidity \\
\hline$R_{l}^{\mathrm{A}}$ & Aqueous-phase chemical reaction terms of species $l$ (chemical production and degradation fluxes) \\
\hline$R_{l^{*}}^{\mathrm{G}}$ & Gas-phase chemical reaction terms of species $l^{*}$ (chemical production and degradation fluxes) \\
\hline$R_{t} / Q_{t}$ & Relative van der Waals subgroup volume/surface area parameters \\
\hline$R_{t}^{\mathrm{H}} / Q_{t}^{\mathrm{H}}$ & Hydrated group volume and surface area parameters \\
\hline$R_{\mathrm{W}} / Q_{\mathrm{W}}$ & $R_{t} / Q_{t}$ values of the water molecule \\
\hline$T(\mathrm{~K})$ & Temperature \\
\hline$x_{\mathrm{W}}$ & Mole fraction of water \\
\hline$x_{i}$ & Mole fraction of component $i$ \\
\hline$z_{i}$ & Number of elementary charges of ion $i$ \\
\hline$\left\{a_{i}\right\}$ & Thermodynamic activity of species $i$ \\
\hline$\{A\}$ etc. & Individual thermodynamic activities \\
\hline$\left\{A_{(\mathrm{aq})}\right\}=m_{A} \gamma_{A}$ & Activity of an un-dissociated compound \\
\hline$\left\{A_{(\mathrm{g})}\right\}$ & Activity of a gas over a particle surface \\
\hline$\left\{A_{(\mathrm{s})}\right\}=m_{s}$ & Activity of a solid \\
\hline$\left\{A^{+}\right\}=m_{A^{+}} \gamma_{A^{+}}$ & Activity of an ion in solution \\
\hline$\left[C^{k}\right]$ & Concentration of WSOC (Water Soluble Organic Carbon) in particle class $k$ \\
\hline$\left\{\mathrm{H}_{2} \mathrm{O}_{(\mathrm{aq})}\right\}=a_{\mathrm{w}}$ & Activity of liquid water in a particle \\
\hline$\alpha_{i}$ & Mass accommodation coefficient of the $i$ th species \\
\hline$\beta$ & Parameter of the integration method \\
\hline$\gamma_{A}$ & Activity coefficient of compound $A$ \\
\hline$\gamma_{i}$ & Molality-based activity coefficient of species $i$ \\
\hline$\gamma_{\mathrm{w}}$ & Molality-based water activity coefficient \\
\hline$\gamma_{j}^{k}$ & Activity coefficient of the $j$ th species in the $k$ th particle/droplet class \\
\hline$\gamma_{ \pm}$ & Mean activity coefficient \\
\hline$\gamma_{+} / \gamma_{-}$ & Activity coefficients of a cation and anion \\
\hline$\varepsilon_{\mathrm{W}}$ & Static permittivity \\
\hline$\kappa_{l}$ & Prefactor of the Henry term (solubility index) \\
\hline$\lambda_{i}(= \pm 1)$ & Factor +1 for products and -1 for reactants \\
\hline
\end{tabular}


Table B1. Continued.

\begin{tabular}{ll}
\hline Symbol/Index & Description \\
\hline$\mu$ & Time-dependent entrainment/detrainment rate \\
$\mu_{i}^{(m)}\left(p, T, n_{j}\right) / \mu_{i}^{(x)}\left(p, T, n_{j}\right)$ & Chemical potentials \\
$v_{i}$ & Molecular speed of gas-phase species $i$ \\
$v_{\mathrm{W}}$ & Partial molar volume of water \\
$\rho_{\mathrm{W}}$ & Density \\
$\sigma_{\mathrm{W}}$ & Surface tension of pure water \\
$v_{i} \mathrm{SR}$ & Droplet solution surface tension \\
$\ln \gamma_{j}^{\mathrm{SR}}(x), \infty$ & Short-range activity coefficient $\gamma_{j}$ of a molecular component $j$ (can be solute or solvent) \\
$\ln \gamma_{i}^{\mathrm{SR}}, \infty$ & Unsymmetrical normalized activity coefficient \\
\hline
\end{tabular}

Table B2. List and description of acronyms.

\begin{tabular}{|c|c|}
\hline Acronym & Description \\
\hline ADCHAM & Aerosol Dynamics, gas- and particle-phase chemistry model for laboratory CHAMber studies \\
\hline ADDEM & Aerosol Diameter Dependent Equilibrium Model \\
\hline AIM & Aerosol Inorganic Model \\
\hline GFEMN & Gibbs free energy minimization model \\
\hline AIOMFAC & Aerosol Inorganic-Organic Mixtures Functional groups Activity Coefficients \\
\hline $\mathrm{BDF}$ & Backward differential formula \\
\hline CAPRAM & Chemical Aqueous Phase RAdical Mechanism \\
\hline CSB & Clegg-Seinfeld-Brimblecombe model \\
\hline E-AIM & Extended Aerosol Inorganic Model \\
\hline EQSAM3 & 3rd Equilibrium Simplified Aerosol Model (EQSAM3) \\
\hline EQUISOLV II & EQUIlibrium SOLVer version 2 \\
\hline ISORROPIA & Thermodynamic equilibrium aerosol model (= "equilibrium" in Greek) \\
\hline ISORROPIA II & Thermodynamic equilibrium aerosol model version 2 \\
\hline LR & Long-range \\
\hline MADM & Multicomponent Aerosol Dynamics Model \\
\hline MARS-A & Model for an Aerosol Reacting System - version A \\
\hline MESA & Multicomponent Equilibrium Solver for Aerosols \\
\hline mod. LIFAC & Modified Liquid Functional Activity Coefficient Model \\
\hline MOSAIC & MOdel for Simulating Aerosol Interactions and Chemistry \\
\hline MR & Middle-range \\
\hline ODE & Ordinary differential equation \\
\hline SPACCIM & Spectral Aerosol Cloud Chemistry Interaction Model \\
\hline SpactMod & SPACCIM activity coefficient module \\
\hline SR & Short-range \\
\hline TMIs & Transition metal ions \\
\hline UHAERO & Inorganic atmospheric aerosol phase equilibrium model (UHAERO) \\
\hline UNIFAC & UNIversal Functional-group Activity Coefficients \\
\hline WSOC & Water soluble organic carbon \\
\hline
\end{tabular}


Acknowledgements. The authors would like to thank Claudia Marcolli and Thomas Peter (ETH Zurich) for the performed water activity measurements of the aqueous test solutions. Furthermore, we would like to thank Andreas Zünd (McGill University, Montreal) for providing a set of additional interaction parameters of AIOMFAC.

Edited by: A. Stenke

\section{References}

Achard, C., Dussap, C. G., and Gros, J. B.: Representation of vapour-liquid equilibria in water-alcohol-electrolyte mixtures with a modified UNIFAC-group-contribution method, Fluid Phase Equilibr., 98, 71-89, 1994.

Amundson, N. R., Caboussat, A., He, J. W., Martynenko, A. V., Savarin, V. B., Seinfeld, J. H., and Yoo, K. Y.: A new inorganic atmospheric aerosol phase equilibrium model (UHAERO), Atmos. Chem. Phys., 6, 975-992, doi:10.5194/acp-6-975-2006, 2006.

Amundson, N. R., Caboussat, A., He, J. W., Martynenko, A. V., Landry, C., Tong, C., and Seinfeld, J. H.: A new atmospheric aerosol phase equilibrium model (UHAERO): organic systems, Atmos. Chem. Phys., 7, 4675-4698, doi:10.5194/acp-7-46752007, 2007.

Ansari, A. S. and Pandis, S. N.: Prediction of multicomponent inorganic atmospheric aerosol behavior, Atmos. Environ., 33, 745757, 1999a.

Ansari, A. S. and Pandis, S. N.: An analysis of four models predicting the partitioning of semivolatile inorganic aerosol components, Aerosol. Sci. Tech., 31, 129-153, doi:10.1080/027868299304200, 1999b.

Antypov, D. and Holm, C.: Osmotic coefficient calculations for dilute solutions of short stiff-chain polyelectrolytes, Macromolecules, 40, 731-738, 2007.

Binkowski, F. S. and Roselle, S. J.: Models-3 Community Multiscale Air Quality (CMAQ) model aerosol component 1. Model description, J. Geophys. Res.-Atmos., 108, 4183, doi:10.1029/2001JD001409, 2003.

Bräuer, P., Tilgner, A., Wolke, R., and Herrmann, H.: Mechanism development and modelling of tropospheric multiphase halogen chemistry: The CAPRAM Halogen Module 2.0 (HM2), J. Atmos. Chem., 70, 19-52, doi:10.1007/S10874-013-9249-6, 2013.

Chang, E. I. and Pankow, J. F.: Prediction of activity coefficients in liquid aerosol particles containing organic compounds, dissolved inorganic salts, and water - Part 2: Consideration of phase separation effects by an X-UNIFAC model, Atmos. Environ., 40, 6422-6436, 2006.

Clegg, S. L., Brimblecombe, P., and Wexler, A. S.: A thermodynamic model of the system $\mathrm{H}^{+}-\mathrm{NH}_{4}^{+}-\mathrm{SO}_{4}^{2-}-\mathrm{NO}_{3}^{-}-\mathrm{H}_{2} \mathrm{O}$ at 298.15 K, J. Phys. Chem. A, 102, 2155-2171, 1998a.

Clegg, S. L., Brimblecombe, P., and Wexler, A. S.: Thermodynamic Model of the System $\mathrm{H}^{+}-\mathrm{NH}_{4}^{+}-\mathrm{SO}_{4}^{2-}-\mathrm{NO}_{3}^{-}-\mathrm{H}_{2} \mathrm{O}$ at Tropospheric Temperatures, J. Phys. Chem. A, 102, 2137-2154, 1998b.

Clegg, S. L., Seinfeld, J. H., and Brimblecombe, P.: Thermodynamic modelling of aqueous aerosols containing electrolytes and dissolved organic compounds, J. Aerosol. Sci., 32, 713-738, 2001.
Clegg, S. L., Kleeman, M. J., Griffin, R. J., and Seinfeld, J. H.: Effects of uncertainties in the thermodynamic properties of aerosol components in an air quality model - Part 1: Treatment of inorganic electrolytes and organic compounds in the condensed phase, Atmos. Chem. Phys., 8, 1057-1085, doi:10.5194/acp-81057-2008, 2008.

Debye, P. and Hückel, E.: Zur Theorie der Elektrolyte, Phys. Z., 24, 185-206, 1923.

Deguillaume, L., Tilgner, A., Schrodner, R., Wolke, R., Chaumerliac, N., and Herrmann, H.: Towards an operational aqueous phase chemistry mechanism for regional chemistrytransport models: CAPRAM-RED and its application to the COSMO-MUSCAT model, J. Atmos. Chem., 64, 1-35, doi:10.1007/S10874-010-9168-8, 2010.

Demaret, J. P. and Gueron, M.: Composite cylinder models of DNA - Application of the electrostatics of the B-Z transition, Biophys. J., 65, 1700-1713, 1993.

Erdakos, G. B., Chang, E. I., Pankow, J. F., and Seinfeld, J. H.: Prediction of activity coefficients in liquid aerosol particles containing organic compounds, dissolved inorganic salts, and water-Part 3: Organic compounds, water, and ionic constituents by consideration of short-, mid-, and long-range effects using X-UNIFAC.3, Atmos. Environ., 40, 6437-6452, 2006.

Ervens, B., George, C., Williams, J. E., Buxton, G. V., Salmon, G. A., Bydder, M., Wilkinson, F., Dentener, F., Mirabel, P., Wolke, R., and Herrmann, H.: CAPRAM 2.4 (MODAC mechanism): An extended and condensed tropospheric aqueous phase mechanism and its application, J. Geophys. Res.-Atmos., 108, 4426, doi:10.1029/2002jd002202, 2003.

Ervens, B., Feingold, G., Clegg, S. L., and Kreidenweis, S. M.: A modeling study of aqueous production of dicarboxylic acids: 2 . Implications for cloud microphysics, J. Geophys. Res.-Atmos., 109, D15206, doi:10.1029/2004JD004575, 2004.

Ervens, B., Turpin, B. J., and Weber, R. J.: Secondary organic aerosol formation in cloud droplets and aqueous particles (aqSOA): a review of laboratory, field and model studies, Atmos. Chem. Phys., 11, 11069-11102, doi:10.5194/acp-1111069-2011, 2011.

Facchini, M., Mircea, M., Fuzzi, S., and Charlson, R.: Cloud albedo enhancement by surface-active organic solutes in growing droplets, Nature, 401, 257-259, 1999.

Facchini, M. C., Decesari, S., Mircea, M., Fuzzi, S., and Loglio, G.: Surface tension of atmospheric wet aerosol and cloud/fog droplets in relation to their organic carbon content and chemical composition, Atmos. Environ., 34, 4853-4857, doi:10.1016/S1352-2310(00)00237-5, 2000.

Fast, J. D., Gustafson, W. I., Easter, R. C., Zaveri, R. A., Barnard, J. C., Chapman, E. G., Grell, G. A., and Peckham, S. E.: Evolution of ozone, particulates, and aerosol direct radiative forcing in the vicinity of Houston using a fully coupled meteorology-chemistry-aerosol model, J. Geophys. Res.-Atmos., 111, D21305, doi:10.1029/2005JD006721, 2006.

Fountoukis, C. and Nenes, A.: ISORROPIA II: a computationally efficient thermodynamic equilibrium model for $\mathrm{K}^{+}$. $\mathrm{Ca}^{2+}-\mathrm{Mg}^{2+}-\mathrm{NH}_{4}^{+}-\mathrm{Na}^{+}-\mathrm{SO}_{4}^{2-}-\mathrm{NO}_{3}^{-}-\mathrm{Cl}^{-}-\mathrm{H}_{2} \mathrm{O}$ aerosols, Atmos. Chem. Phys., 7, 4639-4659, doi:10.5194/acp-7-4639-2007, 2007. 
Fredenslund, A., Jones, R. L., and Prausnitz, J. M.: Groupcontribution estimation of activity coefficients in non-ideal liquid mixtures, AICHE J., 21, 1086-1098, 1975.

Ganbavale, G., Zuend, A., Marcolli, C., and Peter, T.: Improved AIOMFAC model parameterisation of the temperature dependence of activity coefficients for aqueous organic mixtures, Atmos. Chem. Phys., 15, 447-493, doi:10.5194/acp-15-447-2015, 2015.

Gilardoni, S., Liu, S., Takahama, S., Russell, L. M., Allan, J. D., Steinbrecher, R., Jimenez, J. L., De Carlo, P. F., Dunlea, E. J., and Baumgardner, D.: Characterization of organic ambient aerosol during MIRAGE 2006 on three platforms, Atmos. Chem. Phys., 9, 5417-5432, doi:10.5194/acp-9-5417-2009, 2009.

Guo, J., Tilgner, A., Yeung, C., Wang, Z., Louie, P. K. K., Luk, C. W. Y., Xu, Z., Yuan, C., Gao, Y., Poon, S., Herrmann, H., Lee, S., Lam, K. S., and Wang, T.: Atmospheric Peroxides in a Polluted Subtropical Environment: Seasonal Variation, Sources and Sinks, and Importance of Heterogeneous Processes, Environ. Sci. Technol., 48, 1443-1450, doi:10.1021/Es403229x, 2014.

Hairer, E., Nørsett, S. P., and Wanner, G.: Solving Ordinary Differential Equations II: Stiff and differential-algebraic problems, Springer Science \& Business Media, Berlin Heidelberg, 1993.

Hallquist, M., Wenger, J. C., Baltensperger, U., Rudich, Y., Simpson, D., Claeys, M., Dommen, J., Donahue, N. M., George, C., Goldstein, A. H., Hamilton, J. F., Herrmann, H., Hoffmann, T., Iinuma, Y., Jang, M., Jenkin, M. E., Jimenez, J. L., Kiendler-Scharr, A., Maenhaut, W., McFiggans, G., Mentel, Th. F., Monod, A., Prévôt, A. S. H., Seinfeld, J. H., Surratt, J. D., Szmigielski, R., and Wildt, J.: The formation, properties and impact of secondary organic aerosol: current and emerging issues, Atmos. Chem. Phys., 9, 5155-5236, doi:10.5194/acp-9-51552009, 2009.

Hamer, W. J. and Wu, Y. C.: Osmotic Coefficients and Mean Activity Coefficients of Uni-Univalent Electrolytes in Water at $25^{\circ} \mathrm{C}$, J. Phys. Chem. Ref. Data, 1, 1047-1100, 1972.

Hansen, H. K., Rasmussen, P., Fredenslung, A., Schiller, M., and Gmehling, J.: Vapor-liquid equilibria by UNIFAC group contribution. 5. Revision and extension, Ind. Eng. Chem. Res., 30, 2352-2355, 1991.

Henning, S., Rosenørn, T., D’Anna, B., Gola, A. A., Svenningsson, B., and Bilde, M.: Cloud droplet activation and surface tension of mixtures of slightly soluble organics and inorganic salt, Atmos. Chem. Phys., 5, 575-582, doi:10.5194/acp-5-575-2005, 2005.

Herrmann, H.: Kinetics of aqueous phase reactions relevant for atmospheric chemistry, Chem. Rev., 103, 4691-4716, doi:10.1021/Cr020658q, 2003.

Herrmann, H., Tilgner, A., Barzaghi, P., Majdik, Z.-T., Gligorovski, S., Poulain, L., and Monod, A.: Towards a more detailed description of tropospheric aqueous phase organic chemistry: CAPRAM 3.0, Atmos. Environ., 39, 4351-4363, 2005.

Herrmann, H., Schaefer, T., Tilgner, A., Styler, S. A., Weller, C., Teich, M., and Otto, T.: Tropospheric Aqueous-Phase Chemistry: Kinetics, Mechanisms, and Its Coupling to a Changing Gas Phase, Chem. Rev., 115, 4259-4334, doi:10.1021/cr500447k, 2015.

Iliuta, M. C., Thomson, K., and Rasmussen, P.: Extended UNIQUAC model for correlation and prediction of vapourliquid-solid equilibria in aqueous salt systems containing non- electrolytes. Part A. Methanol-water-salt systems, Chem. Eng. Sci., 55, 2673-2686, 2000.

Jacobson, M. Z.: Development and application of a new air pollution modeling system. Part II. Aerosol module structure and design, Atmos. Environ., 31, 131-144, 1997.

Jacobson, M. Z., Tabazadeh, A., and Turco, R. P.: Simulating equilibrium within aerosols and nonequilibrium between gases and aerosols, J. Geophys. Res. Atmos., 101, 9071-9091, 1996.

Kiepe, J., Noll, O., and Gmehling, J.: Modified LIQUAC and Modified LIFACA Further Development of Electrolyte Models for the Reliable Prediction of Phase Equilibria with Strong Electrolytes, Ind. Eng. Chem. Res., 45, 2361-2373, 2006.

Kiriukhin, M. Y. and Collins, K. D.: Dynamic hydration numbers for biologically important ions, Biophys. Chem., 99, 155-168, 2002.

Knopf, D. A., Luo, B. P., Krieger, U. K., and Koop, T.: Thermodynamic dissociation constant of the bisulfate ion from Raman and ion interaction modeling studies of aqueous sulfuric acid at low temperatures, J. Phys. Chem. A, 107, 4322-4332, 2003.

Köhler, H.: The nucleus in and the growth of hygroscopic droplets, Trans. Faraday Soc., 32, 1152-1161, 1936.

Li, J. D., Polka, H. M., and Gmehling, J.: A GE model for single and mixed solvent electrolyte systems. 1. Model and results for strong electrolytes, Fluid Phase Equilibr., 94, 89-114, 1994.

Liu, S., Takahama, S., Russell, L. M., Gilardoni, S., and Baumgardner, D.: Oxygenated organic functional groups and their sources in single and submicron organic particles in MILAGRO 2006 campaign, Atmos. Chem. Phys., 9, 6849-6863, doi:10.5194/acp9-6849-2009, 2009

Maffia, M. C. and Meirelles, A. J. A.: Water activity and pH in aqueous polycarboxylic acid systems, J. Chem. Eng. Data, 46, 582-587, doi:10.1021/je0002890, 2001.

Mao, J., Fan, S., Jacob, D. J., and Travis, K. R.: Radical loss in the atmosphere from $\mathrm{Cu}-\mathrm{Fe}$ redox coupling in aerosols, Atmos. Chem. Phys., 13, 509-519, doi:10.5194/acp-13-509-2013, 2013.

Marcolli, C. and Peter, Th.: Water activity in polyol/water systems: new UNIFAC parameterization, Atmos. Chem. Phys., 5, 15451555, doi:10.5194/acp-5-1545-2005, 2005.

Metzger, S. and Lelieveld, J.: Reformulating atmospheric aerosol thermodynamics and hygroscopic growth into fog, haze and clouds, Atmos. Chem. Phys., 7, 3163-3193, doi:10.5194/acp-73163-2007, 2007.

Metzger, S., Dentener, F., Pandis, S., and Lelieveld, J.: Gas/aerosol partitioning: 1. A computationally efficient model, J. Geophys. Res.-Atmos., 107, 4312, doi:10.1029/2001jd001102, 2002.

Metzger, S., Mihalopoulos, N., and Lelieveld, J.: Importance of mineral cations and organics in gas-aerosol partitioning of reactive nitrogen compounds: case study based on MINOS results, Atmos. Chem. Phys., 6, 2549-2567, doi:10.5194/acp-6-25492006, 2006.

Ming, Y. and Russell, L. M.: Thermodynamic equilibrium of organic-electrolyte mixtures in aerosol particles, AICHE J., 48, 1331-1348, 2002.

Mircea, M., Facchini, M. C., Decesari, S., Fuzzi, S., and Charlson, R. J.: The influence of the organic aerosol component on CCN supersaturation spectra for different aerosol types, Tellus B, 54, 74-81, doi:10.1034/j.1600-0889.2002.00256.x, 2002.

Mohs, A. and Gmehling, J.: A revised LIQUAC and LIFAC model (LIQUAC*/LIFAC*) for the prediction of properties of elec- 
trolyte containing solutions, Fluid Phase Equilibr., 337, 311-322, doi:10.1016/j.fluid.2012.09.023, 2013.

Nenes, A., Pandis, S. N., and Pilinis, C.: ISORROPIA: A New Thermodynamic Equilibrium Model for Multiphase Multicomponent Inorganic Aerosols, Aquat. Geochem., 4, 123-152, 1998.

Nenes, A., Charlson, R. J., Facchini, M. C., Kulmala, M., Laaksonen, A., and Seinfeld, J. H.: Can chemical effects on cloud droplet number rival the first indirect effect?, Geophys. Res. Lett., 29, 1848, doi:10.1029/2002g1015295, 2002.

Peng, C., Chan, M. N., and Chan, C. K.: The hygroscopic properties of dicarboxylic and multifunctional acids: Measurements and UNIFAC predictions, Environ. Sci. Technol., 35, 4495-4501, doi:10.1021/Es0107531, 2001.

Pilinis, C., Capaldo, K. P., Nenes, A., and Pandis, S. N.: MADMA New Multicomponent Aerosol Dynamics Model, Aerosol Sci. Tech., 32, 482-502, 2000.

Pitzer, K. S.: Activity coefficients in electrolyte solutions, CRC Press, 1991.

Prausnitz, J. M., Lichtenthaler, R. N., and De Azevedo, E. G.: Molecular Thermodynamics of Fluid-Phase Equilibria, PrenticeHall Inc., Englewood Cliffs, New Jersey, USA, 2nd Edn., 1986.

Prisle, N. L., Dal Maso, M., and Kokkola, H.: A simple representation of surface active organic aerosol in cloud droplet formation, Atmos. Chem. Phys., 11, 4073-4083, doi:10.5194/acp-11-40732011, 2011.

Prisle, N. L., Ottosson, N., Öhrwall, G., Söderström, J., Dal Maso, M., and Björneholm, O.: Surface/bulk partitioning and acid/base speciation of aqueous decanoate: direct observations and atmospheric implications, Atmos. Chem. Phys., 12, 12227-12242, doi:10.5194/acp-12-12227-2012, 2012.

Pruppacher, H. R. and Klett, J. D.: Microphysics of Clouds and Precipitation, Kluwer Academic Publishers, Dordrecht, the Netherlands, 1997.

Raatikainen, T. and Laaksonen, A.: Application of several activity coefficient models to water-organic-electrolyte aerosols of atmospheric interest, Atmos. Chem. Phys., 5, 2475-2495, doi:10.5194/acp-5-2475-2005, 2005.

Raatikainen, T. and Laaksonen, A.: A simplified treatment of surfactant effects on cloud drop activation, Geosci. Model Dev., 4, 107-116, doi:10.5194/gmd-4-107-2011, 2011.

Ravishankara, A. R.: Heterogeneous and Multiphase Chemistry in the Troposphere, Science, 276, 1058-1065, 1997.

Roldin, P., Eriksson, A. C., Nordin, E. Z., Hermansson, E., Mogensen, D., Rusanen, A., Boy, M., Swietlicki, E., Svenningsson, B., Zelenyuk, A., and Pagels, J.: Modelling non-equilibrium secondary organic aerosol formation and evaporation with the aerosol dynamics, gas- and particle-phase chemistry kinetic multilayer model ADCHAM, Atmos. Chem. Phys., 14, 7953-7993, doi:10.5194/acp-14-7953-2014, 2014.

Russell, L. M., Takahama, S., Liu, S., Hawkins, L. N., Covert, D. S., Quinn, P. K., and Bates, T. S.: Oxygenated fraction and mass of organic aerosol from direct emission and atmospheric processing measured on the R/V Ronald Brown during TEXAQS/GoMACCS 2006, J. Geophys. Res.-Atmos., 114, D00F05, doi:10.1029/2008JD011275, 2009.

Rusumdar, A. J., Tilgner, A., Wolke, R., and Herrmann, H.: Treatment of non-ideality in the multiphase model SPACCIM - Part 2: Model studies on the multiphase chemical processing in deli- quesced particles, Atmos. Chem. Phys. Discuss., in preparation, 2016.

Sander, R.: Compilation of Henry's law constants (version 4.0) for water as solvent, Atmos. Chem. Phys., 15, 4399-4981, doi:10.5194/acp-15-4399-2015, 2015.

Saxena, P., Hudischewskyj, A. B., Seigneur, C., and Seinfeld, J. H.: A comparative study of equilibrium approaches to the chemical characterization of secondary aerosols, Atmos. Environ., 20, 1471-1483, 1986.

Schwartz, S. E.: Mass transport considerations pertinent to aqueous phase reactions of gases in liquid water clouds, in: Chemistry of Multiphase Atmospheric Systems, edited by: Jaeschke, W., Springer, Berlin, 415-471, 1986.

Sehili, A. M., Wolke, R., Knoth, O., Simmel, M., Tilgner, A., and Herrmann, H.: Comparison of different model approaches for the simulation of multiphase processes, Atmos. Environ., 39, 44034417, 2005.

Seinfeld, J. H. and Pandis, S. N.: Atmospheric Chemistry and Physics - From Air Pollution to Climate Change, 2nd Edn., John Wiley \& Sons Inc., New York, USA, 2006.

Shulman, M. L., Jacobson, M. C., Carlson, R. J., Synovec, R. E., and Young, T. E.: Dissolution behavior and surface tension effects of organic compounds in nucleating cloud droplets, Geophys. Res. Lett., 23, 277-280, doi:10.1029/95g103810, 1996.

Simmel, M. and Wurzler, S.: Condensation and activation in sectional cloud microphysical models, Atmos. Environ., 80, 218 236, 2006.

Sorjamaa, R. and Laaksonen, A.: The influence of surfactant properties on critical supersaturations of cloud condensation nuclei, J. Aerosol. Sci., 37, 1730-1736, doi:10.1016/j.jaerosci.2006.07.004, 2006.

Sorjamaa, R., Svenningsson, B., Raatikainen, T., Henning, S., Bilde, M., and Laaksonen, A.: The role of surfactants in Köhler theory reconsidered, Atmos. Chem. Phys., 4, 2107-2117, doi:10.5194/acp-4-2107-2004, 2004.

Svenningsson, B., Rissler, J., Swietlicki, E., Mircea, M., Bilde, M., Facchini, M. C., Decesari, S., Fuzzi, S., Zhou, J., Mønster, J., and Rosenørn, T.: Hygroscopic growth and critical supersaturations for mixed aerosol particles of inorganic and organic compounds of atmospheric relevance, Atmos. Chem. Phys., 6, 1937-1952, doi:10.5194/acp-6-1937-2006, 2006.

Takahama, S., Schwartz, R. E., Russell, L. M., Macdonald, A. M., Sharma, S., and Leaitch, W. R.: Organic functional groups in aerosol particles from burning and non-burning forest emissions at a high-elevation mountain site, Atmos. Chem. Phys., 11, 6367-6386, doi:10.5194/acp-11-6367-2011, 2011.

Tilgner, A. and Herrmann, H.: Radical-driven carbonyl-to-acid conversion and acid degradation in tropospheric aqueous systems studied by CAPRAM, Atmos. Environ., 44, 5415-5422, 2010.

Tilgner, A., Bräuer, P., Wolke, R., and Herrmann, H.: Modelling multiphase chemistry in deliquescent aerosols and clouds using CAPRAM3.0i, J. Atmos. Chem., 70, 221-256, 2013.

Tong, C., Clegg, S. L., and Seinfeld, J. H.: Comparison of activity coefficient models for atmospheric aerosols containing mixtures of electrolytes, organics, and water, Atmos. Environ., 42, 54595482, 2008.

Topping, D.: An analytical solution to calculate bulk mole fractions for any number of components in aerosol droplets after consid- 
ering partitioning to a surface layer, Geosci. Model Dev., 3, 635642, doi:10.5194/gmd-3-635-2010, 2010.

Topping, D., Connolly, P., and McFiggans, G.: Cloud droplet number enhanced by co-condensation of organic vapours, Nat. Geosci., 6, 443-446, doi:10.1038/Ngeo1809, 2013.

Topping, D. O., McFiggans, G. B., and Coe, H.: A curved multicomponent aerosol hygroscopicity model framework: Part 1 - Inorganic compounds, Atmos. Chem. Phys., 5, 1205-1222, doi:10.5194/acp-5-1205-2005, 2005a.

Topping, D. O., McFiggans, G. B., and Coe, H.: A curved multicomponent aerosol hygroscopicity model framework: Part 2 - Including organic compounds, Atmos. Chem. Phys., 5, 1223-1242, doi:10.5194/acp-5-1223-2005, 2005b.

Topping, D. O., McFiggans, G. B., Kiss, G., Varga, Z., Facchini, M. C., Decesari, S., and Mircea, M.: Surface tensions of multicomponent mixed inorganic/organic aqueous systems of atmospheric significance: measurements, model predictions and importance for cloud activation predictions, Atmos. Chem. Phys., 7, 2371-2398, doi:10.5194/acp-7-2371-2007, 2007.

Tuckermann, R. and Cammenga, H. K.: The surface tension of aqueous solutions of some atmospheric watersoluble organic compounds, Atmos. Environ., 38, 6135-6138, doi:10.1016/j.atmosenv.2004.08.005, 2004.

Wexler, A. S. and Seinfeld, J. H.: The Distribution of AmmoniumSalts among a Size and Composition Dispersed Aerosol, Atmos. Environ. A-Gen, 24, 1231-1246, doi:10.1016/09601686(90)90088-5, 1990 .

Wolke, R. and Knoth, O.: Time-integration of multiphase chemistry in size-resolved cloud models, Appl. Numer. Math., 42, 473-487, 2002.

Wolke, R., Sehili, A. M., Simmel, M., Knoth, O., Tilgner, A., and Herrmann, H.: SPACCIM: A parcel model with detailed microphysics and complex multiphase chemistry, Atmos. Environ., 39, 4375-4388, 2005.

Yan, W., Topphoff, M., Rose, C., and Gmehling, J.: Prediction of vapor-liquid equilibria in mixed-solvent electrolyte systems using the group contribution concept, Fluid Phase Equilibr., 162, 97-113, 1999.

Yu, S. C., Dennis, R., Roselle, S., Nenes, A., Walker, J., Eder, B., Schere, K., Swall, J., and Robarge, W.: An assessment of the ability of three-dimensional air quality models with current thermodynamic equilibrium models to predict aerosol $\mathrm{NO}_{3}^{-}$, J. Geophys. Res.-Atmos., 110, D07S13, doi:10.1029/2004jd004718, 2005.
Zaveri, R. A., Easter, R. C., and Wexler, A. S.: A new method for multicomponent activity coefficients of electrolytes in aqueous atmospheric aerosols, J. Geophys. Res.-Atmos., 110, D02201, doi:10.1029/2004jd004681, 2005a.

Zaveri, R. A., Easter, R. C., and Peters, L. K.: A computationally efficient Multicomponent Equilibrium Solver for Aerosols (MESA), J. Geophys. Res.-Atmos., 110, D24203, doi:10.1029/2004JD005618, 2005b.

Zaveri, R. A., Easter, R. C., Fast, J. D., and Peters, L. K.: Model for Simulating Aerosol Interactions and Chemistry (MOSAIC), J. Geophys. Res.-Atmos., 113, D13204, doi:10.1029/2007JD008782, 2008.

Zhang, Y., Seigneur, C., Seinfeld, J. H., Jacobson, M., Clegg, S. L., and Binkowski, F. S.: A comparative review of inorganic aerosol thermodynamic equilibrium modules: similarities, differences, and their likely causes, Atmos. Environ., 34, 117-137, doi:10.1016/S1352-2310(99)00236-8, 2000.

Zhang, Y., Pun, B., Vijayaraghavan, K., Wu, S. Y., Seigneur, C., Pandis, S. N., Jacobson, M. Z., Nenes, A., and Seinfeld, J. H.: Development and application of the model of aerosol dynamics, reaction, ionization, and dissolution (MADRID), J. Geophys Res.-Atmos., 109, D01202, doi:10.1029/2003jd003501, 2004.

Zuend, A., Marcolli, C., Luo, B. P., and Peter, T.: A thermodynamic model of mixed organic-inorganic aerosols to predict activity coefficients, Atmos. Chem. Phys., 8, 4559-4593, doi:10.5194/acp8-4559-2008, 2008.

Zuend, A., Marcolli, C., Booth, A. M., Lienhard, D. M., Soonsin, V., Krieger, U. K., Topping, D. O., McFiggans, G., Peter, T., and Seinfeld, J. H.: New and extended parameterization of the thermodynamic model AIOMFAC: calculation of activity coefficients for organic-inorganic mixtures containing carboxyl, hydroxyl, carbonyl, ether, ester, alkenyl, alkyl, and aromatic functional groups, Atmos. Chem. Phys., 11, 9155-9206, doi:10.5194/acp11-9155-2011, 2011. 